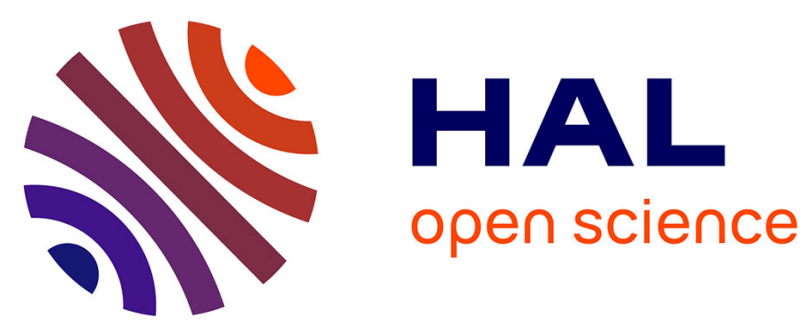

\title{
Development of image texture analysis technique for boulder distribution measurements: Applications to asteroids Ryugu and Itokawa
}

Naoya Tanabe, Yuichiro Cho, Eri Tatsumi, Tatsuki Ebihara, Koki Yumoto, Tatsuhiro Michikami, Hideaki Miyamoto, Tomokatsu Morota, Chikatoshi Honda, Patrick Michel, et al.

\section{To cite this version:}

Naoya Tanabe, Yuichiro Cho, Eri Tatsumi, Tatsuki Ebihara, Koki Yumoto, et al.. Development of image texture analysis technique for boulder distribution measurements: Applications to asteroids Ryugu and Itokawa. Planetary and Space Science, 2021, 204, pp.105249. 10.1016/j.pss.2021.105249 . insu-03381697

\section{HAL Id: insu-03381697 https://hal-insu.archives-ouvertes.fr/insu-03381697}

Submitted on 17 Oct 2021

HAL is a multi-disciplinary open access archive for the deposit and dissemination of scientific research documents, whether they are published or not. The documents may come from teaching and research institutions in France or abroad, or from public or private research centers.
L'archive ouverte pluridisciplinaire HAL, est destinée au dépôt et à la diffusion de documents scientifiques de niveau recherche, publiés ou non, émanant des établissements d'enseignement et de recherche français ou étrangers, des laboratoires publics ou privés. 
archives-ouvertes

\section{Development of image texture analysis technique for boulder distribution measurements: Applications to asteroids Ryugu and Itokawa}

Naoya Tanabe, Yuichiro Cho, Eri Tatsumi, Tatsuki Ebihara, Koki Yumoto, Tatsuhiro Michikami, Hideaki Miyamoto, Tomokatsu Morota, Chikatoshi Honda, Patrick Michel, et al.

\section{To cite this version:}

Naoya Tanabe, Yuichiro Cho, Eri Tatsumi, Tatsuki Ebihara, Koki Yumoto, et al.. Development of image texture analysis technique for boulder distribution measurements: Applications to asteroids Ryugu and Itokawa. Planetary and Space Science, Elsevier, 2021, 204, pp.105249. 10.1016/j.pss.2021.105249 . insu-03381697

HAL Id: insu-03381697 https://hal-insu.archives-ouvertes.fr/insu-03381697

Submitted on 17 Oct 2021

HAL is a multi-disciplinary open access archive for the deposit and dissemination of scientific research documents, whether they are published or not. The documents may come from teaching and research institutions in France or abroad, or from public or private research centers.
L'archive ouverte pluridisciplinaire HAL, est destinée au dépôt et à la diffusion de documents scientifiques de niveau recherche, publiés ou non, émanant des établissements d'enseignement et de recherche français ou étrangers, des laboratoires publics ou privés. 


\title{
Development of image texture analysis technique for boulder distribution measurements: Applications to asteroids Ryugu and Itokawa
}

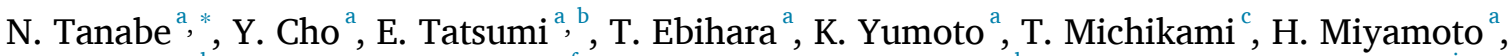 \\ T. Morota ${ }^{\text {a }}{ }^{d}$, C. Honda ${ }^{e}$, P. Michel ${ }^{\mathrm{f}}$, K.A. Otto ${ }^{g}$, O.S. Barnouin ${ }^{\mathrm{h}}$, K. Yoshioka ${ }^{\mathrm{a}}$, H. Sawada ${ }^{\mathrm{i}}$, \\ Y. Yokota ${ }^{i},{ }^{j}$, N. Sakatani ${ }^{k}$, M. Hayakawa ${ }^{i}$, R. Honda ${ }^{j}$, S. Kameda ${ }^{k}$, M. Matsuoka ${ }^{i}$, M. Yamada ${ }^{1}$ \\ T. Kouyama ${ }^{\mathrm{m}}$, H. Suzuki ${ }^{\mathrm{n}}$, K. Ogawa ${ }^{\circ}$, S. Sugita ${ }^{\mathrm{a}}$ \\ ${ }^{a}$ The University of Tokyo, 7-3-1 Ho ngo, Bunkyo, Tokyo, 113-0033, Japan \\ ${ }^{\mathrm{b}}$ Instituto de Astrofisica de Canrias, Calle Vía Láctea, s/n, 38205, San Cristóbal de La Laguna, Santa Cruz de Tenerife, Spain \\ ${ }^{\mathrm{c}}$ Fa culty of Engineering, Kindai University, Hiroshima Campus, 1 Taka ya Umenobe, Higashi-Hiroshima, Hiroshima, 739-2116, Japan \\ ${ }^{\mathrm{d}}$ Nagoya University, Nagoya, 464-8601, Japan \\ e University of Aizu, Aizu-Wakamatsu, 965-8580, Japan \\ ${ }^{\mathrm{f}}$ Université Côte d'Azur, Observatoire de la Côte d'Azur, CNRS, Laboratoire Lagrange, CS 34229, 06304, Nice Cedex 4, France \\ ${ }^{g}$ German Aerospace Center (DLR), Institute of Planetary Research, 12489, Berlin, Germany \\ ${ }^{\mathrm{h}}$ Applied Physics Laboratory/Johns Hopkins University, 11100 Johns Hopkins Ro ad, Laurel, MD, 20723, USA \\ ${ }^{\mathrm{i}}$ Institute of Space and Astronautical Science (ISAS), Japan Aerospace Exploration Agency (JAXA), Sagamihara, 252-5210, Japan \\ ${ }^{\mathrm{j}}$ Kochi University, Ko chi, 780-8520, Japan \\ ${ }^{\mathrm{k}}$ Rikkyo University, Tokyo, 171-8501, Japan \\ ${ }^{1}$ Planetary Exploration Research Center, Chiba Institute of Technology, Narashino, 275-0016, Japan \\ ${ }^{\mathrm{m}}$ National Institute of Advanced Industrial Science and Technology, Tokyo, 135-0064, Japan \\ ${ }^{\mathrm{n}}$ Meiji University, Kawasaki, 214-8571, Japan \\ ${ }^{\circ}$ Ko be University, Kobe, 657-8501, Japan
}

A R T I C L E I N F O

\section{Keywords:}

Asteroids

Rubble pile as teroids

Image analysis

Boulders

Ryugu and itokawa

\begin{abstract}
A B S T R A C T
Recent asteroid missions have revealed that many sub-kilometer asteroids are rubble piles. Large parts of their surfaces are covered with boulders larger than tens of centimeters. An evaluation of the abundance and size distribution of boulders provides clues to understand surface processes on boulder-covered asteroids. Here we report a new me thod that automatically measures the abun dance of small boulders (sub-pixel to a few pixels), whose boundaries cannot be recognized with visual inspection, by quantifying the surface radiance variation that occurs during the spinning of the asteroid. After validating our approach with previous boulder coun ting data, we apply this method to images of the asteroids Ryugu and Itokawa, which were visited by JAXA's Hayabusa and Hayabusa2, and obtain a global distribution of the boulders larger than $0.75-3 \mathrm{~m}$, which corresponds to $1.5-6$ pixels. We find that the boulder number density of this size range is smaller (1) on the western bulge than on the eastern hemisphere and (2) on the equatorial ridge than on the higher latitudes, both of which exceed the number density of boulders $>5 \mathrm{~m}$ by an order of magnitude. The boulder size distribution at 1.25-20 m shows that the boulders smaller than $1 \mathrm{~m}$ are more abundant at the equator than at mid-latitudes, while those larger than $1 \mathrm{~m}$ in diameter are more abundant at midlatitudes than at the equator. This contrast suggests size-dependent migration of boulders in the latitudinal direction. We also find that the typical boulder size (the size reaching the cumulative areal coverage of $50 \%)$ is $1.9 \mathrm{~m}$ at the equatorial region $\left(10^{\circ} \mathrm{S}-10^{\circ} \mathrm{N}\right)$ while it is $2.6 \mathrm{~m}$ at mid-latitudes $\left(40^{\circ} \mathrm{S}-50^{\circ} \mathrm{S}, 40^{\circ} \mathrm{N}-\right.$ $\left.50^{\circ} \mathrm{N}\right)$. The typical boulder size is also smaller in the western bulge $(2.0-2.2 \mathrm{~m})$. We construct global maps of the power-law index of the size frequency distribution of boulders and find minor variations over the entire surface of Ryugu $(-2.53 \pm 0.03)$ for boulders larger than $1.25 \mathrm{~m}$. This small variation suggests homogeneous size sorting processes on Ryugu. Surface roughness does not show a significant correlation with the v-band albedo but shows a high anti-correlation $(\mathrm{R}=-0.73)$ with the current geological slope on the eastern hemisphere. Our method is useful enhancement of smooth area detection and boulder distribution characterization that will be applicable to other planetary explorations in the future, including those of Pho-
\end{abstract}

\footnotetext{
* Corresponding author.
} 


\section{Introduction}

Recent near-Earth asteroid (NEA) missions have revealed that many sub-kilometer asteroids, such as Itokawa, Ryugu, and Bennu, are rubble piles with high abundance of boulders (Fujiwa ra et al., 2006; Watanabe et al., 2019; Lauretta et al., 2019). These observations are consistent with theoretical predictions that many small asteroids would be formed from catastrophic disruption of larger parent bodies and subsequent re-accumulations of frag ments (Walsh et al., 2018; Michel \& Richardson 2014; Durda et al., 1998). These spacecraft observations also revealed great details of these small asteroids (e.g., Miyamoto et al., 2007; Sugita et al., 2019). For example, average particle size on Itokawa, Ryugu and Bennu, are several tens of meters to several meters in diameter (Saito et al., 2007., Sugita et al., 2019; Michikami et al., 2019; Walsh et al., 2019). Thus, analysis of such sizes of boulders is useful for understanding the surface processes and properties, such as mass movement, resurfacing, spectral change, and thermal inertia.

The size and spatial distributions of boulders were investiga ted by a number of previous studies by visual counting (e.g., Dombard et al., 2010; Pajola et al., 2015; Michikami et al., 2008). These analyses focused on the spatial density of boulders (Dombard et al., 2010), sizefrequency distributions (Michikami et al., 2008), and the shape and orientation of boulders (Nakamura et al., 2008; Jawin et al., 2020). When multiband imag es were available, the color of boulders was obtained to discuss their compositions, degree of space weathering and solar heating (Sugita et al., 2019; Walsh et al., 2019). On Itokawa, spatially heterogeneous boulder number density is thought to have been caused by granular motion, which resulted from repeated seismic waves generated by impact events (Miyamoto et al., 2007). On Ryugu, local highresolution images show an evidence of regolith migration from equatorial ridge towards the current low potential region, such as imbricated boulders and run-up regolith on larger boulders (Sugita et al., 2019).

The size-frequency distribution (SFD) of boulders on planetary bodies is used to investigate the mass flow of surface materials, size sorting effect on the surface, and formation process of regolith and boulders. Assuming that the boulders are fragments of larger disintegrated boulders, the SFD of boulders follows a power law. The fragmentation of boulders can be described as a fracture process by collisional cascade, in which self-similar fragments are produced (Turcotte, 1997). The power-law index varies depending on many reasons, such as different mechanical strengths of boulders (Tanaka et al., 1996) or the fragmentation process of boulders (Hartmann, 1969). Surface processes that sort the size of boulders (e.g., mass flow, convection, displacement by impacts (Mottola et al., 2015; Miyamoto et al., 2007; Daly and Schultz, 2016)) subsequently affect the index. The actual power-law index of the SFD of boulders ranges from -2 to -4 on planets, moons, asteroids and comets (e.g., Turcotte, 1997; Thomas et al., 2001). On Itokawa, for example, Michikami et al. (2008) reported regional va riations in the power law index: $3.1 \pm 0.1$ (global average), $-2.8 \pm 0.1$ (head region), $-3.2 \pm 0.1$ (body region), suggesting a material difference between the two bodies that constitute the head and body of Itokawa, which may have been originally separated and then eventually merged together. This two-body merge scenario was also supported by the density contrast between each body (Lowry et al., 2014; Kanamaru and Sasaki, 2019). Ryugu exhibits an abundance of boulders larger than $20 \mathrm{~m}$ and regional variation of boulder number density between the eastern and western hemispheres; furthermore, lower latitudes host fewer boulders (Michikami et al., 2019). The power-law index of boulder distribution is smaller (gentler) than that of Itokawa. This difference wa s interpreted as the result of the burial of small boulders by even smaller boulders, because large boulders $(\sim 10 \mathrm{~m})$ were buried by small boulders ( $\sim 1 \mathrm{~m}$ ) (Michikami et al., 2019). However, except for some high-resolution images acquired locally during Hayabusa2's touchdown operations, the boulder distribution was measured for the size range larger than $5 \mathrm{~m}$, while the global coverage of such boulders was only $20-35 \%$. The boulders larger than $1 \mathrm{~m}$ cover $80-90 \%$. The distribution of boulders including such smaller boulders (sub-meter to a few meters) on Ryugu was not investiga ted globally because of the insufficient image resolutions.

Because boulders smaller than $\sim 5$ pixels cannot be recognized in a reliable way (Murdoch et al., 2015), "smoother" or "rougher" textures found on images was used to infer the surface roughness or the abundance of small boulders (sub-pixel to a few pixels) (Fig. 1). However, there is no method to convert the qualitative textures of images to actual boulder number densities. Moreover, counting hundreds of thousands of boulders on the entire asteroid surface requires an enormous amount of time and effort (e.g., Michikami et al., 2019 for Ryugu, Walsh et al., 2019 for Bennu). This poses a problem when, for example, a quick evaluation/selection of the safest landing site from the entire asteroid surface is needed (Kikuchi et al., 2020). For such lander missions, including recent and future sample-return missions, analyzing the distribution of sub-meter boulders is important for ensuring spacecraft safety and efficient sample collection (see Fig. 2).

Thus, in this study, we develop a method that estimates the abundance of boulders smaller than the resolution limit ( $\sim 5$ pixels) from the texture of the surface. Our method calculates the standard deviation of radiance of a target area using images from different viewing angles. We apply this novel technique to the images of Ryugu and Itokaw a to evaluate the abundance of boulders, which were indistinguishable with the visual counting approach. We obtain maps of boulders coverage of $0.75-40 \mathrm{~m}$, which cover $80-90 \%$ surface of Ryugu, and a map of power-law index of SFDs to investigate the degree of local size-sorting on this asteroid.

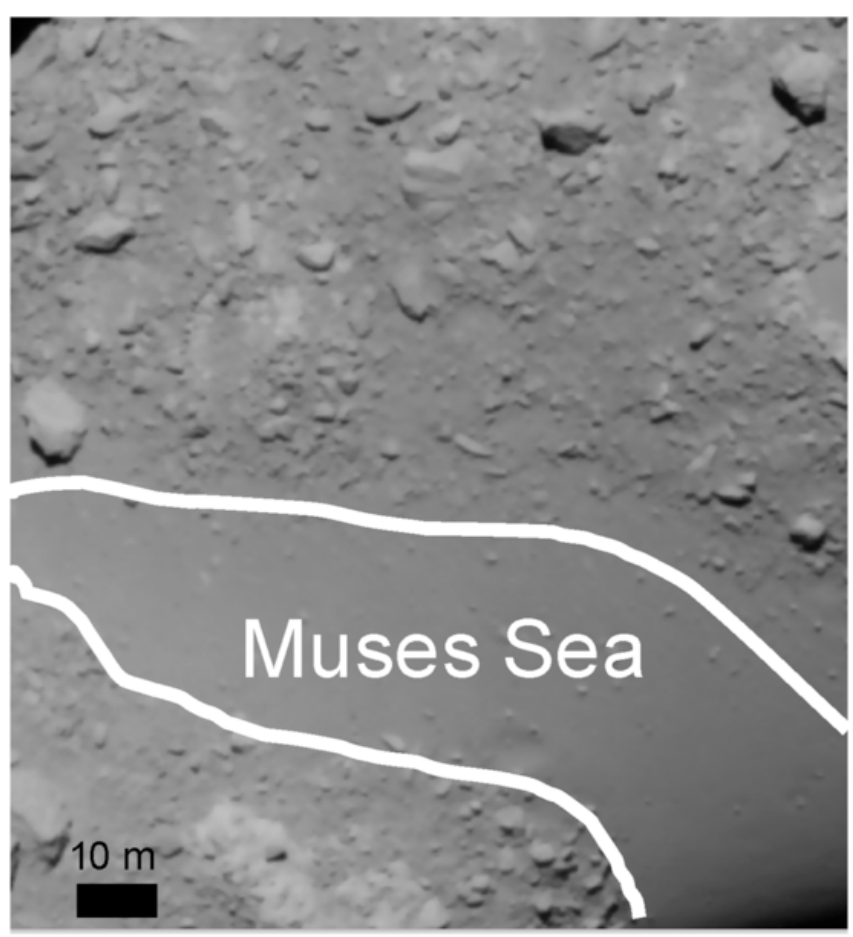

Fig. 1. Image of Itokawa taken by Hayabusa. Note the smooth surface texture at Muses Sea and the surrounding rough surface texture. (Image ID: ST_2493031594). 


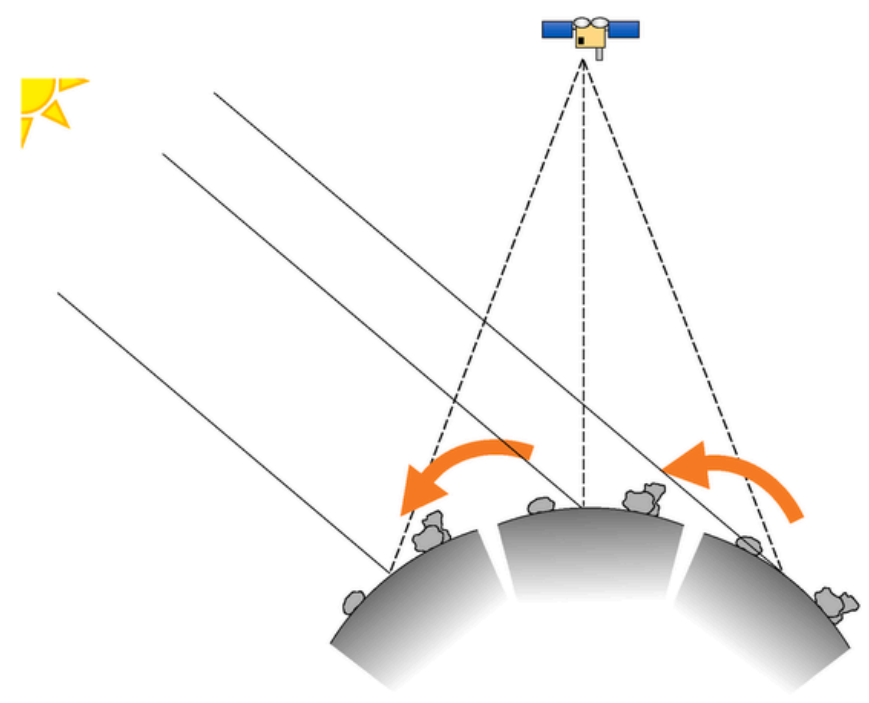

Fig. 2. Concept of our method. We use images of the same region taken from different angles while the asteroid spins. The position of a region of interest occupies different pixels in each image, but the pixels corresponding to the region are tracked and the standard deviation of their radiance is measured.

\section{Image analysis method}

In this section, we outline a method to estimate the abundance of small boulders based on the qualitative texture of the images.

\subsection{Measurement principle}

We quantify the texture, or the "smoothness of an area", using the standard deviation of radiance in multiple images of a given target area. Because Hayabusa2 observed Ryugu while hovering above the surface, the solar incidence angle and emission angle to/from a certain area changed as the asteroid spins. Within this region, the inclination and shape of individual particles or boulders generate an observable radiance variation due to the varying reflection from individual particles/boulders. For example, on a surface that hosts boulders significantly larger than pixel scales, the asteroid's spin changes its radiance significantly because illumination and observation conditions, such as incidence, emission, and phase angles, change according to the direction and angle of individual boulder facets. In contrast, if a number of small particles cover the area of interest (i.e., the area appears smooth in an image), the inter-image deviation of radiance within the area is much smaller than that of a rougher area with larger particles. This is because the more particles (regolith, pebbles and boulders) of different orientations and shapes cover, the more homogeneous is the photometry of the pixel as a whole. We did not take the morphology or surface texture of individual boulders into account in this automated process. Although rougher boulders make $\sigma_{\mathrm{sp}}$ higher, the effect of such surface features on $\sigma_{\mathrm{sp}}$ is bracketed in the error of the boulder coverage.

Below, we show that the standard deviation of radiance of the same region observed with at different geometries indicates the particle size on the target region. To formulate this relation, we define $\sigma_{s p}$ as the standard deviation of radiance of each pixel due to the spin of the asteroid. The value of $\sigma_{s p}$ qualitatively shows the size of the boulders and will be correlated with actual boulder size and its coverage in section 2 . 4.

$\sigma_{s p}^{2}=\frac{1}{N} \sum_{i=1}^{N}\left(\frac{f_{i}-\bar{f}}{\bar{f}}\right)^{2}$

$\left(N\right.$ : number of imag es with different observation angles, $f_{i}$ : radiance of a pixel for each viewing angle, $\bar{f}$ : average of radiance of the pixel of interest, observed in $N$ images, $\sigma_{s p}$ : standard deviation of radiance of the pixel of interest).

First, we measured the radiance of individual pixels in an image using asteroid Ryugu L2b image data. The standard deviation of the radiance over different images with different viewing angles was obtained by the tracking of each pixel. For example, if a pixel on a specific boulder is in the area of interest, the specific pixel appears at different pixels in different images. The location of the pixel on the boulder is tracked over different images by assigning each pixel in the image with a polygon ID of the shape model (SHAPE_SFM_3M_v20180804; Watanabe et al., 2019). The radiance of the pixel was measured in each image to derive the standard deviation of the radiance over multiple images. For this corregistration process, we used the information on the position and attitude of the spacecraft at the time of image acquisition. Then the image of the shape model was reproduced from the viewing angle exactly the same as the real ONC-T images. The difference in the asteroid rim position was less than 1 pixel between the real image and simulated image at low-to mid-latitudes $\left(45^{\circ} \mathrm{S}-45^{\circ} \mathrm{N}\right)$. The shape model we used had relatively large uncertainties in high-latitudes because of the lack of the images used to create the model (Watanabe et al., 2019). Thus, we calibrated the coverage of boulders between $45^{\circ} \mathrm{S}$ and $45^{\circ} \mathrm{N}$. Our results on the even higher latitudes $\left(45-60^{\circ}\right)$ were extrapolated based on the calibration established at $<45^{\circ}$, although the position of asteroid's rim in the simulated images matched those of the actual images within 1 pixel on average. The boulder number density measurements at the high latitudes require further study with an updated shape model. The size of the facet of the shape model was comparable or smaller than each pixel in the image $(\sim 0.6 \mathrm{~m} / \mathrm{pix}$ for Ryugu, $\sim 0.4 \mathrm{~m}$ /pix for Itokawa) because the shape model consists of $3 \mathrm{mil}-$ lion triangular facets with a side of $\sim 0.4 \mathrm{~m}$. If one pixel in the image covered multiple facetss on the shape model, the image pixel was assigned to the facet with the center closest to the pixel center. Thus, every pixel in an asteroid image was assigned to a specific facet on the shape model. The image pixels assigned to the same polygon (facet) ID were regarded as observing the same location of the asteroid.

We calculated the incidence/emission angles of each facet from the shape model. The number of images $N$ to obtain the standard deviation of the radiance of each pixel was 5 . Note that $\sigma_{s p}$ is irrelevant to absolute boulder size at this stage because our approach relies only on pixel scales. The size of boulders of interest can be changed by changing the resolution of image sets by binning. This feature is used in Section 3.2 to derive the power-law index of the boulder sizefrequency distribution. From the power-law index and size-frequency distribution, we calculate the typical boulder size (the size reaching the cumulative areal coverage of 50\%) for each region.

\subsection{Dataset}

We used the images acquired during multiple observation campaigns at different altitudes: so-called home position (HP, $20 \mathrm{~km}$ above the surface, $2.0 \mathrm{~m} /$ pix, Ryugu spins $3^{\circ}$ per image; 127 images obtained on July 10th, 2018) and mid-altitude covering $50^{\circ} \mathrm{S}-50^{\circ} \mathrm{N}(5 \mathrm{~km}$, $0.5 \mathrm{~m} / \mathrm{pix}$; 91 images obtained on August 1st, 2018). We conducted the same analysis using 60 images of Itokawa (ST_2420699984-ST_2426434412), which were obtained while the asteroid rotated at an interval of $3^{\circ}$ between subsequent images. The resolution of the Itokawa images is $0.4 \mathrm{~m} /$ pix. We acquired these images from JAXA's Data Archives and Transmission System (DARTS). The shape models of Itokaw a (Stereo Photoclinometry (SPC) model version 5.04) and Ryugu (SHAPE_SFM_3M_v20180804) were used to calculate incidence/emission angles conditions for the imag es and to derive geologic slopes of the asteroid surface. 


\subsection{Model caveats}

We note two caveats for potential bias in $\sigma_{s p}$ due to the photometric effects caused by different incidence/emission angles and shadows of boulders. First, different degrees of variations in the incidence/ emission angles result in wider radiance variations of pixels in low latitudes than in high latitudes. Because our method does not require photometric correction, the different degrees of the photometric effects lead to an overestimation in boulder number density at lower latitudes: the equatorial regions tend to show larger variation in pixel radiance because the variation in the photometric effects tends to be larger around the equator (Fig. 3a). Because of the effects, widely different incidence/emission angles yield a large variation in apparent pixel radiance among the images. Without any corrections, the degree of overestimation would be $0.5 \%$ in $\sigma_{s p}$ regardless of the abundance of boulders, when the average of $\sigma_{s p}$ was $5-10 \%$. To reduce the radiance deviation due to the photometric effect, we made a criterion on incidence and emission angles toward and from individual facets: $30^{\circ} \leq i, e \leq 50^{\circ}$ and $|i-e| \leq 4.5^{\circ}$ ( $i$ : incidence angle, $e$ : emission angle). Based on this criterion we removed the deviation by extreme photometric conditions: $7 \%$ of facets at $45^{\circ} \mathrm{S}-45^{\circ} \mathrm{N}$ were excluded. The facets that did not meet the criteria were not used for our $\sigma_{s p}$ calculations. With this correction, the apparent radiance variation due to the photometric effect is within the level of the calibration accuracy (section 2.5). The thresholds of the angles were set to make the number of radiance data larger than 1000 . If the conditions of the incidence/ emission angles are too strict, the number of data points (facets) becomes very small. For example, if $|i-e| \leq 4.0^{\circ}$ then the number of pixels at $0-10^{\circ} \mathrm{N}$ falls to only $\sim 100$, hindering the assessment of global boulder number distribution.

The second caveat with our method is involved in the processing of shadows cast by boulders. Without any corrections, the boulder number density would be estimated to be lower than the actual value in areas where numerous boulders cast many shadows. This is because our algorithm removes the shadow associated with boulders from $\sigma_{s p}$ calculations. We excluded facets showing a radiance of less than $1 \%$ of the global average. Because numerous boulders cast shadows as the asteroid spins on a boulder-rich surface, one boulder on the surface could be in the shadow of nearby boulders in another image. As a result, relatively boulder-poor areas in the boulder-rich region were selectively used for our calculation. This procedure led to a systematic underestimation of boulder coverage by $1.0-1.5 \%$ in the northern hemisphere, where boulder coverage is $20-25 \%$ (boulders of 5-20 m). Nevertheless, such underestimation would result in $1.0-1.5 \%$ in coverage, which is within the level of our calibration ac- curacy (section 2.5). With this procedure, $\sim 6 \%$ of the area in $25-45^{\circ} \mathrm{N}$ and $\sim 2 \%$ of $25-45^{\circ} \mathrm{S}$ were excluded from the calculation. The north-south contrast occurred because the northern hemisphere was in winter in our dataset and tended to show shadows that are more abundant.

\subsection{Calibration of $\sigma_{s p}$}

In this section, we calibrate $\sigma_{s p}$, the standard deviation of the radiance among five images, with the boulder number density obtained by visual counting using higher-resolution images. First, we calculated $\sigma_{s p}$ globally with the low-resolution image sets obtained from the spacecraft home position (pixel resolution $\sim 2 \mathrm{~m}$ /pix). We then correlated the coverage of the pixels showing $\sigma_{s p}$ higher than a threshold with the coverage of boulders (\%) obtained from visual boulder-counting data of selected regions (Fig. 4).

For this calibration, we counted boulders in higher-resolution images acquired from the mid-altitude operation $(\sim 0.5 \mathrm{~m} / \mathrm{pix})$. We used the images of the 7 candidate sites $(100 \mathrm{~m} \times 100 \mathrm{~m})$ that were selected for Hayabusa2's first touchdown (Kikuchi et al., 2020). The smallest

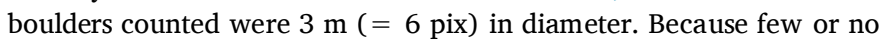
boulders larger than $12 \mathrm{~m}$ were found in the regions we used for calibration, we calculated the coverage of boulders of 3-12 m, which would occupy 1.5-6 pixels in the home-position images used for making the $\sigma_{s p}$ maps. The coverage of the $3-12 \mathrm{~m}$ boulders in the seven $100 \times 100 \mathrm{~m}$ areas were between 12 and 27, providing the "ground truth" for the calibration. Then, we constructed $\sigma_{s p}$ maps in these regions using the lower-resolution images taken from the HP. Each region was expressed by $50 \times 50$ pixel because the pixel resolution was $2 \mathrm{~m} /$ pix. Note that boulders smaller than $12 \mathrm{~m}$ were no longer resolvable with these HP images.

To measure the cumulative boulder number density in a certain area $\left(\mathrm{km}^{-2}\right)$, which is usually measured using the visual counting approach, we calculated the ratio of pixels that showed a $\sigma_{s p}$ larger than a threshold $\left(\sigma_{0}\right)$, to the total pixel number in the areas. The area coverage of $\sigma_{s p}>\sigma_{0}$ in the $50 \times 50$ pixel area wa salculated in each area and correlated with the boulder coverage of 1.5-6 pixel (0.75-3 m) measured with our boulder-counting analyses (Fig. 4). We found that the $\sigma_{0}=0.1$ yields the highest correlation between the coverage of pixels showing $\sigma_{s p}>\sigma_{0}$ and the actual coverage of boulders (Fig. 5). The threshold could differ for different cameras or optical setups, therefore this calibration should be performed when a different instrument is used. The fitting line betw een "the coverage of the region exhibiting $\sigma_{s p}$ $>10 \%$ " and "actual coverage of boulders (3-12 m)" was used as the calibration line to convert any $\sigma_{s p}$ distribution to the coverage of boul- (a)

(b) (c)

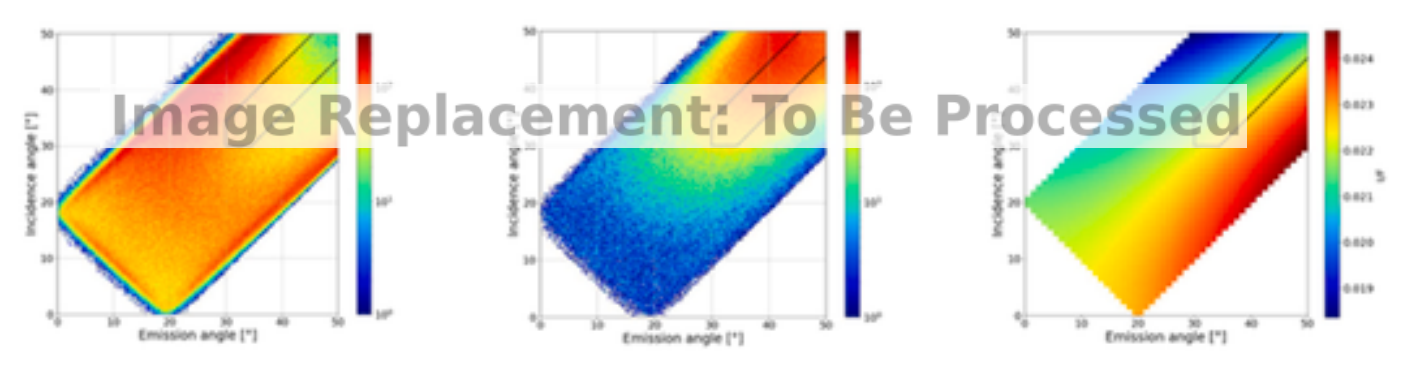

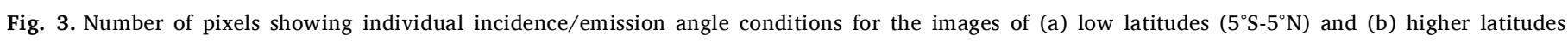

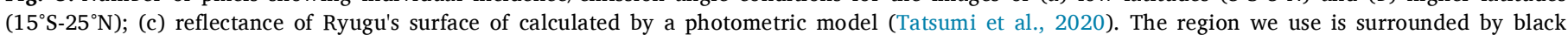

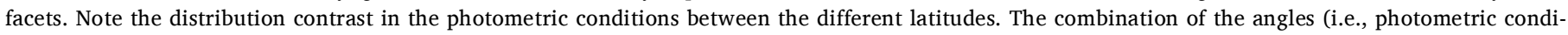

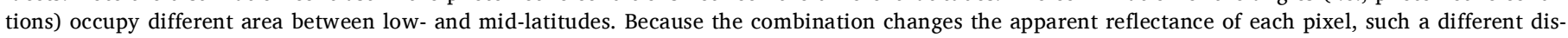

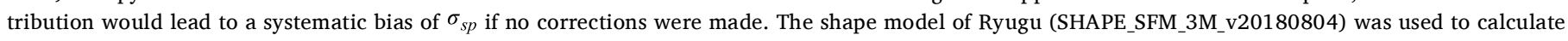
the incidence/emission angles. 
(a)Low resolution ( 2 m/pix, HP)

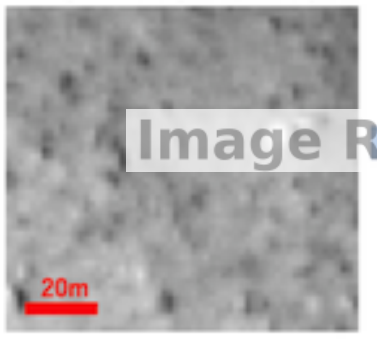

(b)

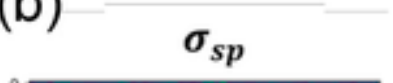

(c) High resolution ( $0.5 \mathrm{~m} / \mathrm{pix}$, Mid-Alt)
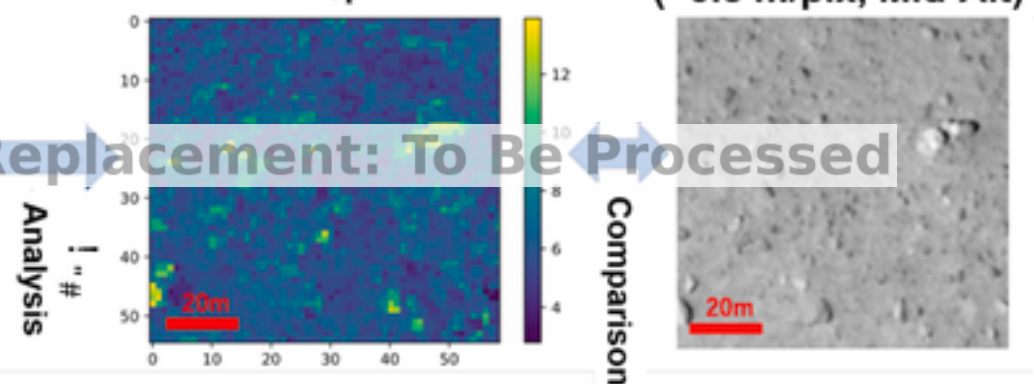

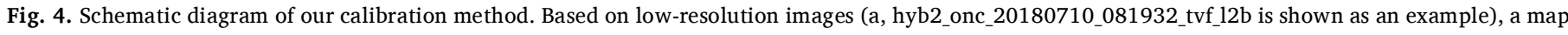

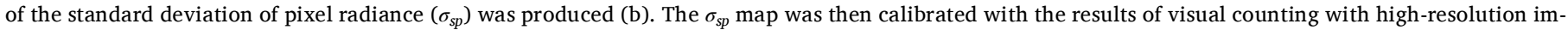
ages (c, hyb2_onc_20180801_141202_tbf_12b).

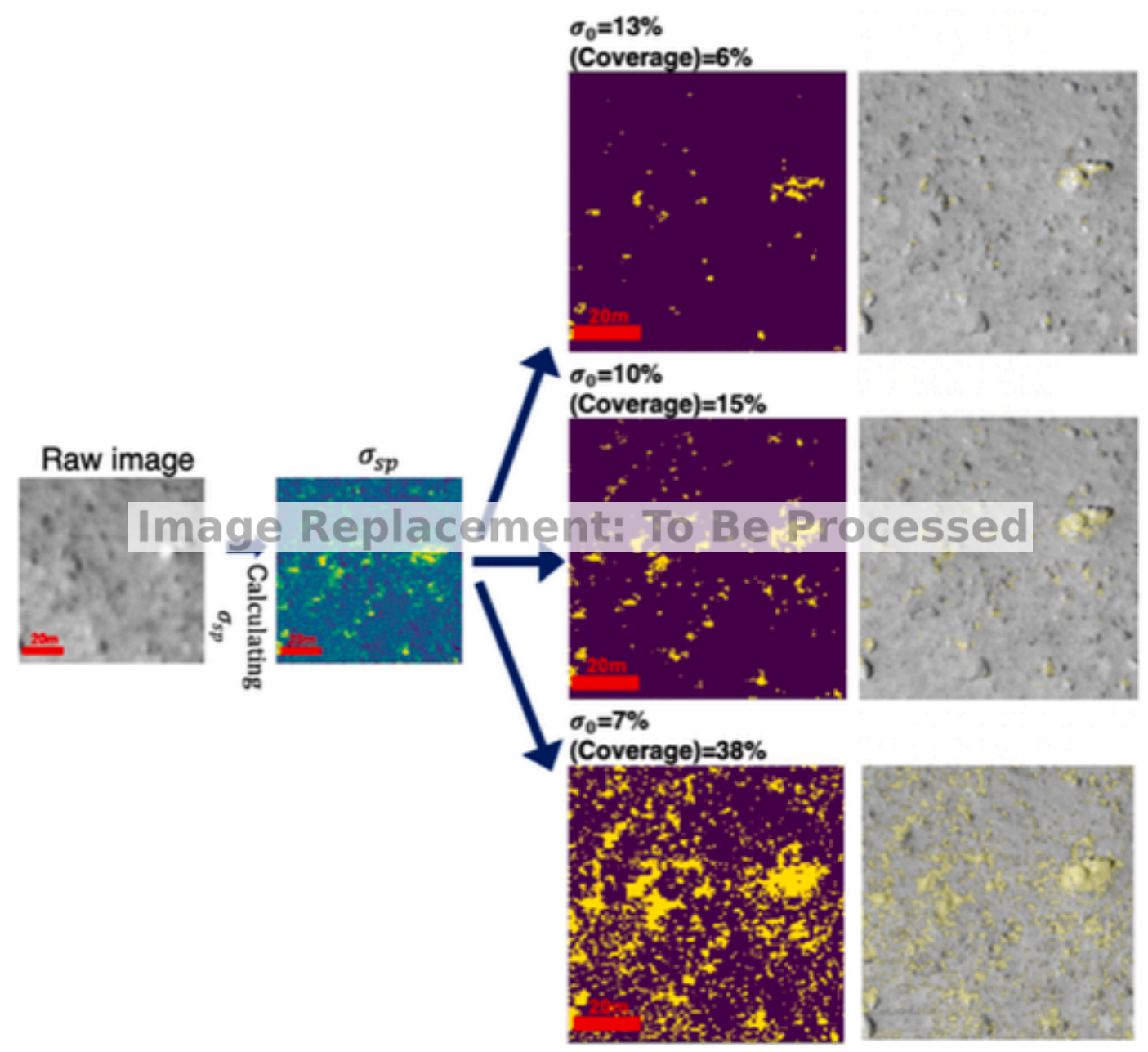

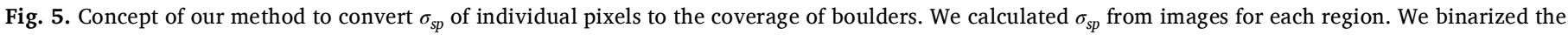

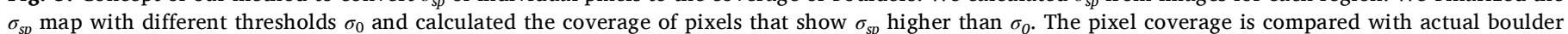
coverage of the region. The same images as Fig. 4 were used. The figures on the right show the binary maps and their context.

ders (Fig. 6). The size of the area in which we calculate coverage can vary depending on the objective of the analysis. The root mean square of the coverage prediction was $1.85 \%$ when boulder coverages were $10-30 \%$ (Fig. 6a). This value was used in this study as an intrinsic uncertainty in our measurements.

\subsection{Validation}

To validate our method, we derived the boulder coverage with our calibration line and compared the results with the visual boulder counting data reported in a previous study (Michikami et al., 2019). We calculated $\sigma_{s p}$ that corresponds to the boulders of 5-20 m to match the size range reported by Michikami et al. (2019). To conduct this analysis, we changed the effective resolution of the images of Ryugu from $2.0 \mathrm{~m} / \mathrm{pix}$ 
(a)

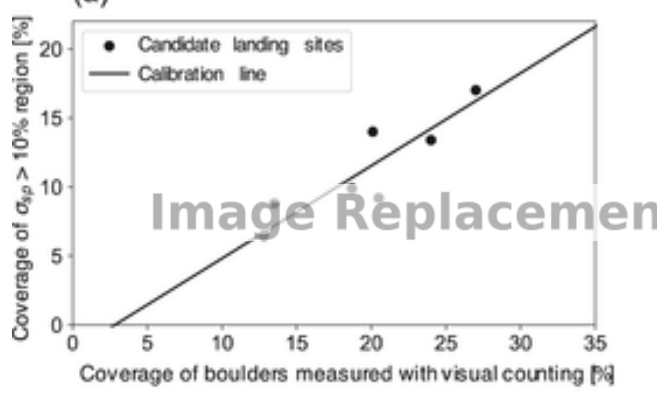

(b)

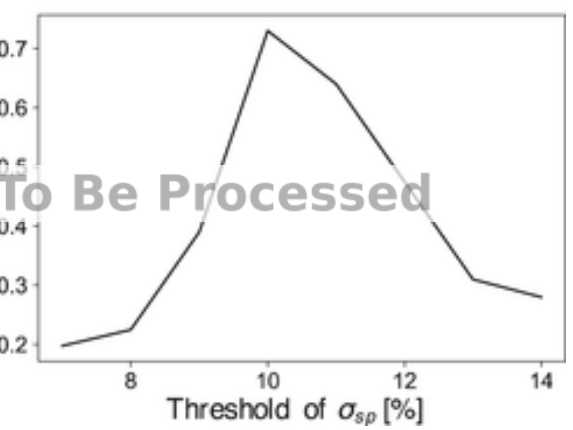

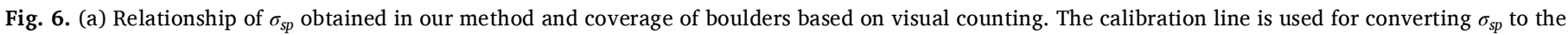

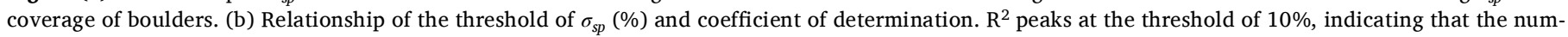
ber of pixels showing $\sigma_{s p}>10 \%$ is most correlated with the coverage of boulders larger than 1.5 pix.

to $3.3 \mathrm{~m} /$ pix by binning the images with $0.5 \mathrm{~m} /$ pix resolution. We found that the coverage values obtained with our calibration line were consistent with the visual counting results (Fig. 7) within the range of $2 \sigma$. The RMS error in coverage was $1.5 \%$ (7.9\% relative error when normalized by the median coverage of $19 \%$ ) when compared to the visual counting data. The amount of error in our analyses wa s comparable to the intrinsic error in visual counting. This amount of error includes those from systematic overestimation by photometric conditions and shadows discussed in Section 2.1. This result demonstrates that our method can derive the coverage of boulders ( $>1.5$ pix) from the texture of the surface, including the boulders that are too small to be visually distinguished. The high correlation betw een the coverage of boulders analyzed by our method and those analyzed by visual counting also demonstrates the capability of changing the size range of boulders by artificially changing the resolution of images (i.e., binning). Such a spatial resolution control will be used to derive the power-law exponent of the boulder SFD in section 3.2.

\section{Boulder distribution on ryugu}

In this section, we show the global distribution of boulders (0.75-3 $\mathrm{m}$ in diameter) on Ryugu, which were too small to investigate globally in previous studies. We produced global maps for boulder number densities, derived the distribution in the longitudinal and latitudinal directions of boulders larger than $0.75 \mathrm{~m}$, and compared the result with previous studies. We then construct a global map of the power-law index of boulder SFDs by producing lower-resolution images $(\sim 1.7,3.3$, $6.7 \mathrm{~m} / \mathrm{pix}$ ) and repeating our method on these images. We compared these parameters with the v-band albedo and surface slope obtained in previous studies.

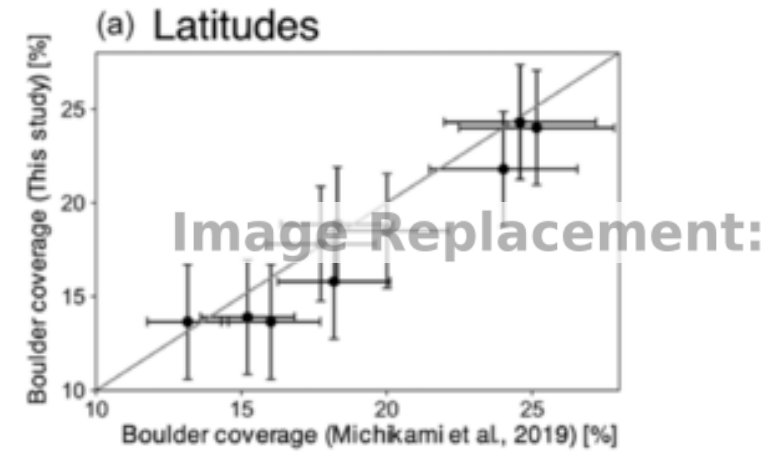

\subsection{Distribution of boulders in different longitudes and latitudes}

Fig. 8a shows the global distribution of small boulders $(0.75-3 \mathrm{~m})$, which was not mapped in previous studies because of insufficient image resolutions. We investigated the features of boulder distribution in the longitudinal and latitudinal directions at a boulder scale smaller than that visually counted in previous studies (Figs. 6 and 7). First, the longitudinal distribution of the boulder number density indicates that the coverage of boulders on the eastern hemisphere is larger than that on the western bulge (Fig. 9a). Our study reveals that the dichotomy in boulder number density observed at $>5 \mathrm{~m}$ (Michikami et al., 2019) extends to sub-meter boulders (Fig. 9b). The area of smallest boulder coverage $(0.75-3 \mathrm{~m})$ is found on the $\sim 100 \mathrm{~m} \times 100 \mathrm{~m}$ area on the trough (Fig. 8c).

Second, the latitudinal distribution of boulders of $0.75-3 \mathrm{~m}$ shows that fewer boulders are present at lower latitudes $\left(20^{\circ} \mathrm{S}-20^{\circ} \mathrm{N}\right)$ (Fig. 10a), extending the trend found for boulders ( $>5 \mathrm{~m}$ ) (Fig. 10b). This result is consistent with the geomorphological evidence that boulders at low latitudes are covered with finer boulders (Michikami et al., 2019). One interpretation to account for this distribution is the different mobility due to the particle size (e.g., Phillips et al., 2006).

\subsection{Power-law index $\alpha$ of boulder size-frequency distribution}

In this section, we obtain the power-law index $\alpha$ for boulder SFDs globally in the size range 10 times smaller than those obtained studied in previous studies. We then produce $\alpha$ maps of Ryugu and Itokaw a, to investiga te the size distribution of boulders on these asteroids.

\subsubsection{Distribution on ryugu}

We investigated the spatial distribution of the power-law index and the size distribution of boulders on Ryugu. By $2 \times 2$ or $4 \times 4$

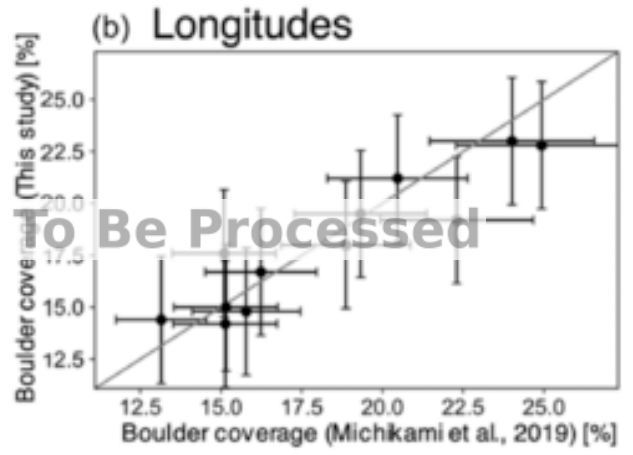

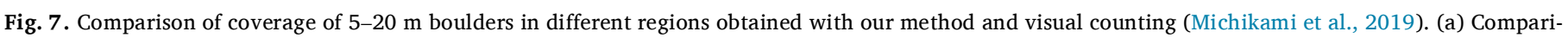
son in different latitudinal bins and in (b) longitudinal bins. The two results are consistent within the uncertainties. 
(a)

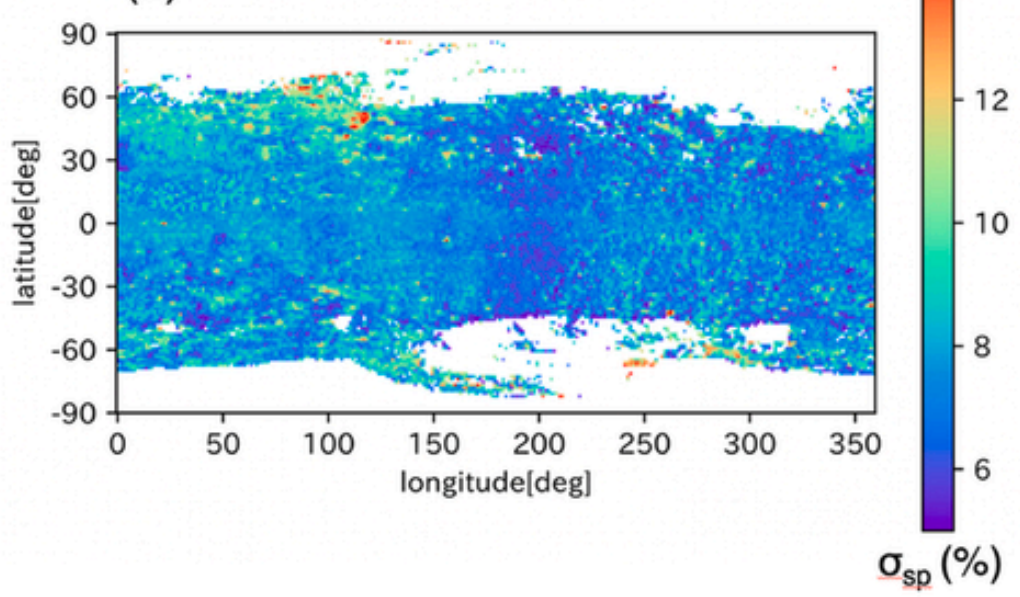

(b)

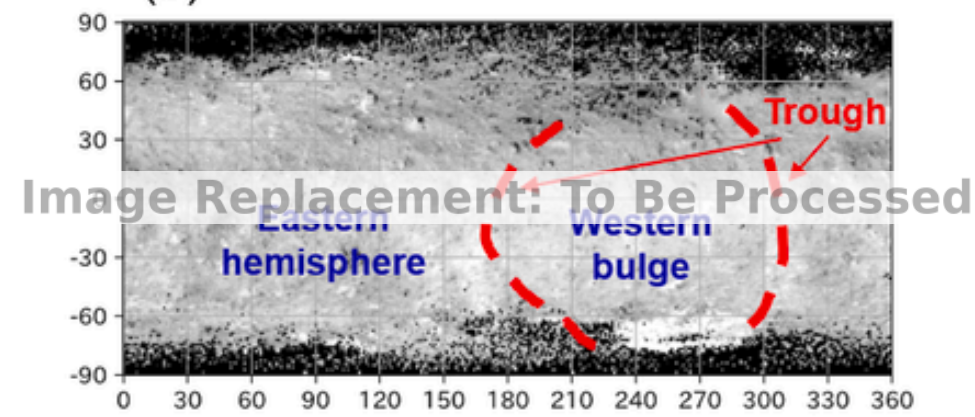

(c)

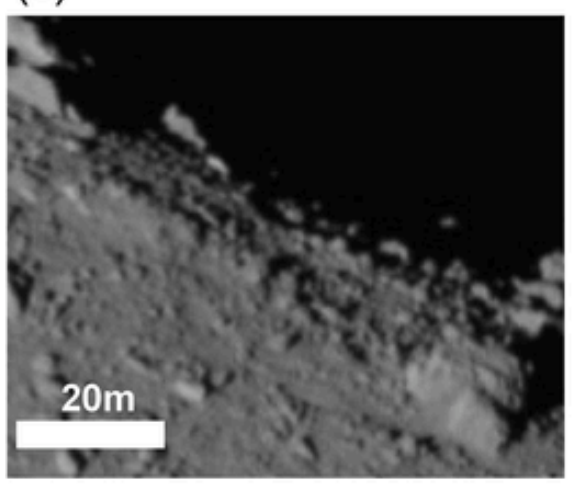

(d)

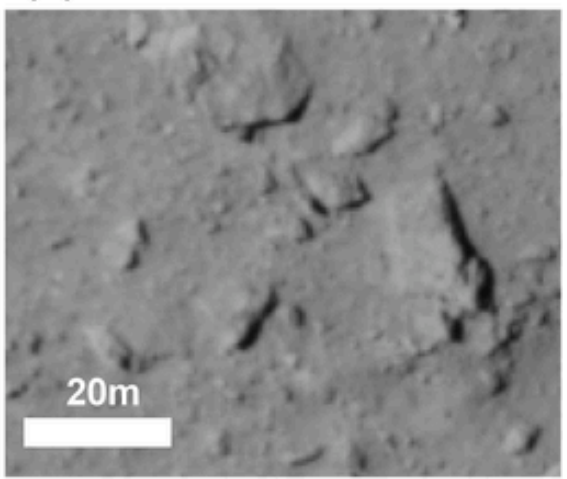

Fig. 8. (a) Global map of the standard deviation of radiance, which indicates the coverage of the boulders of $0.75-3 \mathrm{~m}$. The map was constructed with the images taken at mid-altitude (August 1, 2018) and shape model of Ryugu. One pixel in the map is $0.5 \mathrm{~m} \times 0.5 \mathrm{~m}$. (b) Context image of Ryugu's surface. (c) Smoothest area found on the trough $\left(200^{\circ} \mathrm{E}, 30^{\circ} \mathrm{N}\right)$ (hyb2_onc_20180801_180109_tvf_l2b). (d) Roughest area found at mid-latitude on the eastern hemisphere $\left(110^{\circ}, 50^{\circ} \mathrm{N}\right)$ (hyb2_onc_20180801_230638_tvf_12b).

binning of the images obtained at the altitude of $5 \mathrm{~km}(0.5 \mathrm{~m} / \mathrm{pix})$, we reduced the effective pixel resolution and obtained the coverage of boulders corresponding to 1.5-6 pix in each image. The power-law index $\alpha$ was calculated for each facet with the four cumulative coverage data at 1.25, 2.5, 5.0 and $10 \mathrm{~m}$ (Fig. 11).

The global map of the power-law index $\alpha$ shows a very small variation in $\alpha$ over all of Ryugu's surface (Fig. 12). Note that the map tends to show the smaller features of $\alpha$ in the high latitudes because the area specified by $5^{\circ} \times 5^{\circ}$ is almost half of that in the equatorial region. However, this latitudinal dependence of area size does not affect the derivation of $\sigma_{s p}$ or $\alpha$ because $\sigma_{s p}$ is calculated at a much finer scale (individual facets $\sim 0.4 \mathrm{~m}$ ). The average and standard deviation of the index were -2.53 and 0.03 , respectively. This small variation indicates that the lateral boulder size-sorting process is either weak or 
(a) Distribution of small boulders $(0.75-3 \mathrm{~m})$

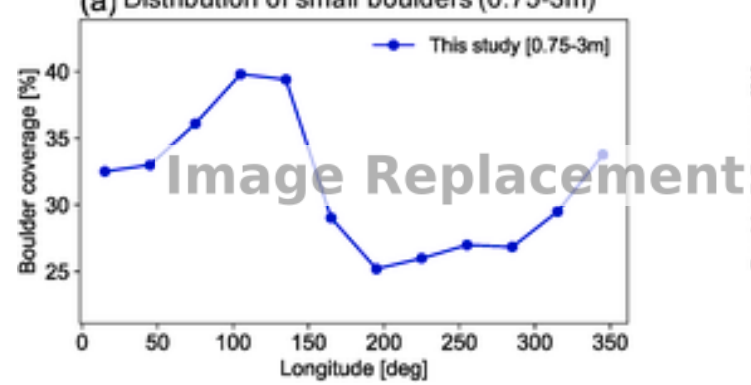

(b) Distribution of boulders $(5-20 \mathrm{~m})$

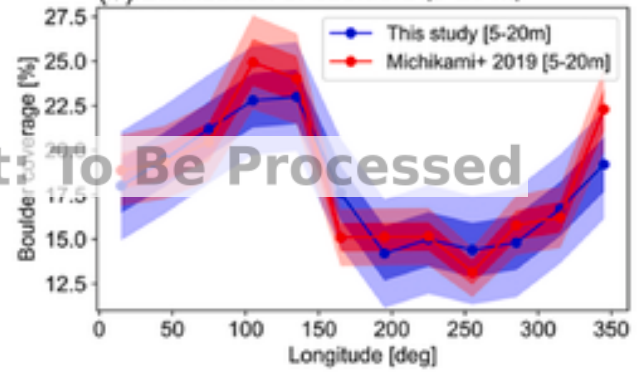

Fig. 9. (a) Longitudinal boulder distribution and profile of coverage of boulders (0.75-3 m). (b) Profile compared with Michikami et al. (2019) for boulder size in the range 5-20 m. Darker and lighter shades show $1 \sigma$ and $2 \sigma$ errors, respectively. The global map of $\sigma_{s p}$ shown in Fig. 8 was used to calculate the coverage of boulders $(0.75-3 \mathrm{~m}$ and 5-20 m).

(a) Distribution of small boulders $(0.75-3 \mathrm{~m})$

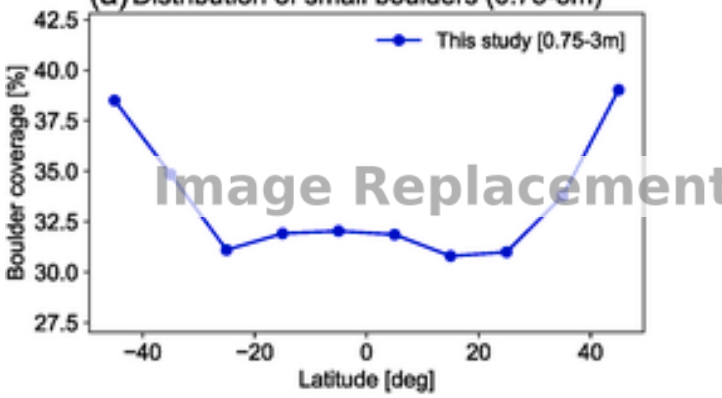

(b) Distribution of boulders (5-20 m)

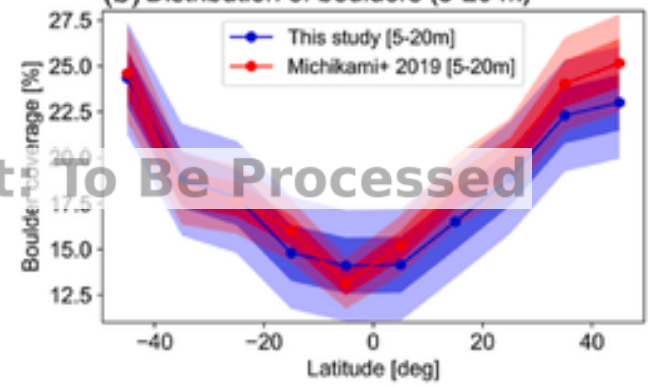

Fig. 10. (a) Latitudinal profile of boulders $(0.75-3 \mathrm{~m})$ obtained with our method. Lower latitudes exhibit lower boulder coverage. Darker and lighter shades show $1 \sigma$ and $2 \sigma$ errors, respectively. (b) Coverage of boulders in latitudinal bins. The results obtained using our method are compared with those obtained by Michikami et al. (2019) in the size range of 5-20 m. The global map of $\sigma_{s p}$ shown in Fig. 8 was used to calculate the coverage of boulders $(0.75-3 \mathrm{~m}$ and $5-20 \mathrm{~m})$.

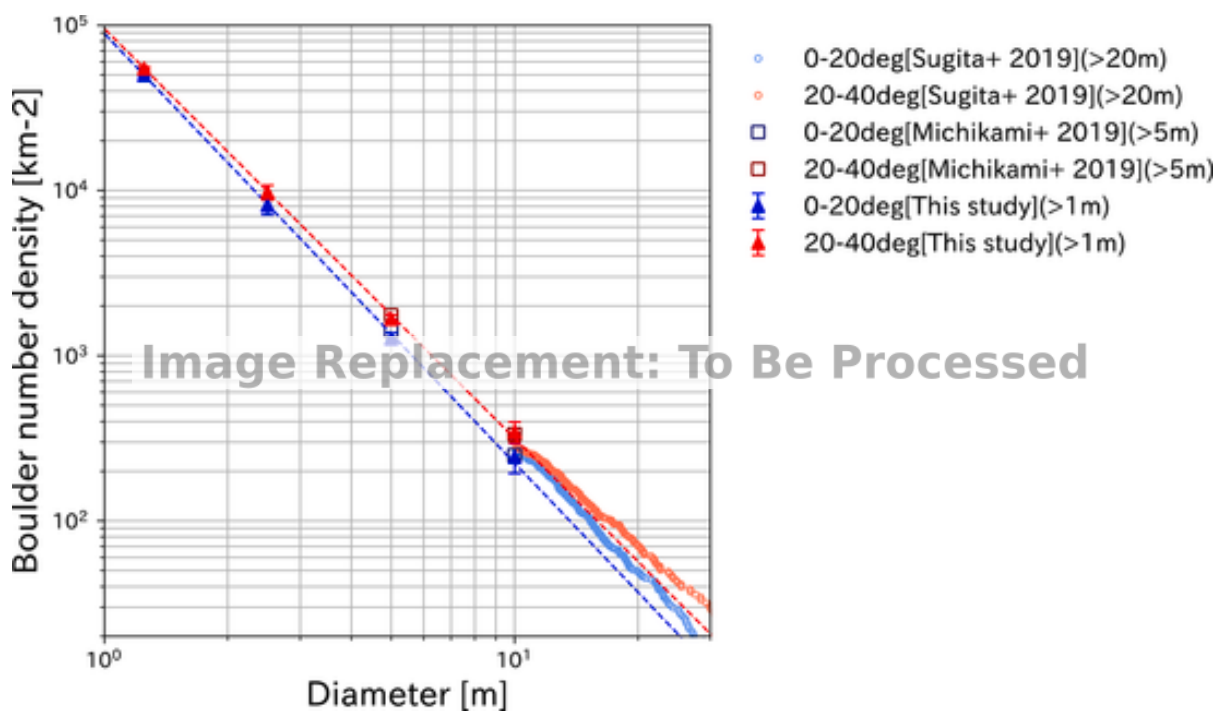

Fig. 11. SFD of boulders in low- $\left(20^{\circ} \mathrm{S}-20^{\circ} \mathrm{N}\right)$ and mid-latitudes $\left(40^{\circ} \mathrm{N}-20^{\circ} \mathrm{N}, 40^{\circ} \mathrm{S}-20^{\circ} \mathrm{S}\right)$. Cumulative boulder number density data obtained in this study are plotted with those of previous studies. The data by Michikami et al. (2019) are plotted at the diameters 5 and $10 \mathrm{~m}$. The power-law fitting lines (dashed lines) are constructed using the data points obtained in this study. Note the crossover at $<1 \mathrm{~m}$. The global map of $\sigma_{s p}$ shown in Fig. 8 was used to calculate the coverage of boulders $(0.75-3 \mathrm{~m}$ and $5-20 \mathrm{~m})$.

very homogeneous on Ryugu, producing no particularly smooth regions and other rough regions as observed on Itokawa. We also found that the power-law index decreases (gentler) with decreasing boulder size globally. This global trend is consistent with the result of visual counting in a few local areas, where boulders of several to tens of centimeters were measured with high-resolution images (Michikami et al., 2019). The power-law index for the boulders of $1.25-10 \mathrm{~m}$ is consistent with that reported for the boulders larger than $5 \mathrm{~m}$ (Michikami et al., 2019) equal to $-2.53 \pm 0.05$, but shallower than the result inferred by the data for those larger than $20 \mathrm{~m}$ (Sugita et al., 2019) because of the different size ranges (Table 1 ).

The latitude-dependent SFDs using the boulders of 1.25-20 m show that boulders smaller than $1 \mathrm{~m}$ are more abundant at the equator than in the mid-latitudes, while those larger than $1 \mathrm{~m}$ are more abundant in the mid-latitudes than on the equator (Fig. 11). This different crossover in boulder SFD depending on latitude could be because of the size- 


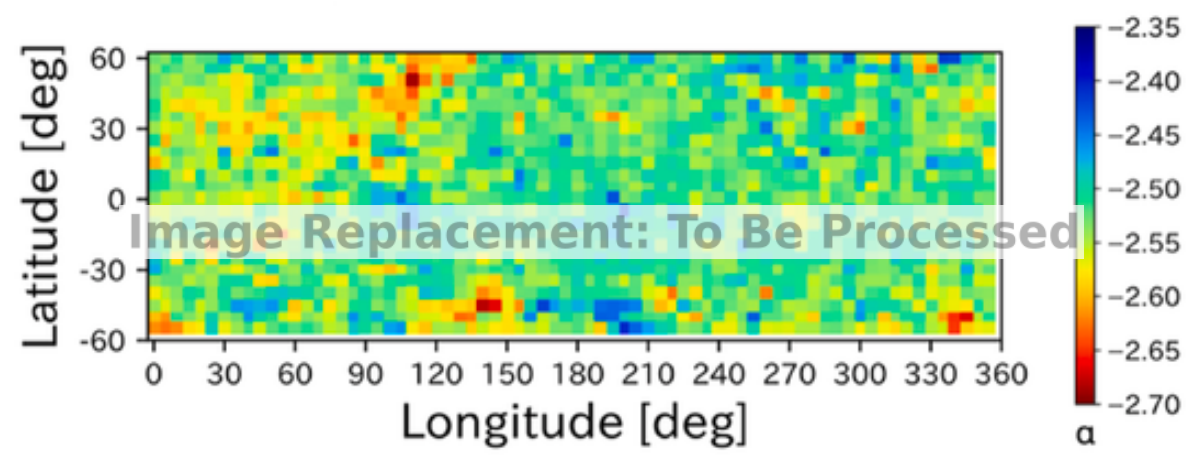

Fig. 12. Distribution of power-law indices on Ryugu. One pixel in the map is $5^{\circ} \times 5^{\circ}$.

Table 1

Power-law indices of boulder size-frequency distributions in low latitudes, mid latitudes, eastern hemisphere $\left(0-135^{\circ}\right.$ and $\left.330-360^{\circ}\right)$, and western bulge $\left(180-300^{\circ}\right)$ (Sugita et al., 2019). The longitudes $135-180^{\circ}$ and $300-330^{\circ}$ are where the fossae are located and not categorized either east or west.

\begin{tabular}{lllll}
\hline $\begin{array}{l}\text { Boulder size } \\
\text { range }\end{array}$ & $\begin{array}{l}\text { Low } \\
\text { latitudes }(0- \\
\left.20^{\circ}\right)\end{array}$ & $\begin{array}{l}\text { Mid latitudes }\left(20-40^{\circ}\right) \\
\end{array}$ & $\begin{array}{l}\text { Eastern } \\
\text { hemisphere }(0- \\
135, \\
\left.330-360^{\circ}\right)\end{array}$ & $\begin{array}{l}\text { Western } \\
\text { Bulge }(180- \\
\left.300^{\circ}\right)\end{array}$ \\
\hline $\begin{array}{c}\text { 20 m (Sugita } \\
\text { et al., 2019) }\end{array}$ & $2.71 \pm 0.04$ & $2.58 \pm 0.04$ & $2.66 \pm 0.04$ & $2.62 \pm 0.04$ \\
$\begin{array}{c}1.25-20 \mathrm{~m} \\
\text { (This study) }\end{array}$ & $2.60 \pm 0.05$ & $2.52 \pm 0.05$ & $2.52 \pm 0.05$ & $2.55 \pm 0.05$ \\
\hline
\end{tabular}

dependent mobility of boulders which may favor the travel of larger distances of smaller boulders, although further study is required to assess how such a size-dependent mobility works on small asteroids. One possible scenario is that the boulders smaller than $1 \mathrm{~m}$ flowed towards the equator in the paleo high-spin-rate era of Ryugu, while larger (5-10 m) ones were left at mid-latitudes; the $<1 \mathrm{~m}$ boulders are still on the equatorial ridge because the current geopotential gradient is not steep enough for the small boulders to flow down to the mid-latitudes. Another hypothesis to explain this latitudinal distribution would be that the small boulders are buried by the larger ones in the mid latitudes due to regolith migration processes, such as the Brazil nut effect (Miyamoto et al., 2007). These smaller particles would have been deposited before/during the paleo high-spin-rate or broken down in place.

\subsubsection{Distribution on itokawa}

We applied our method to the imag es of Itokawa $(0.4 \mathrm{~m} / \mathrm{pix})$ and obtained the roughness $\left(\sigma_{s p}\right)$ map and power-law index map (Fig. 13). The lowest $\sigma_{s p}$ occurs in the smooth regions named Muses Sea and Sagamihara. The averages of the power-law index for global, head, body, west and east regions were $-3.6,-2.8,-2.9$ and -3.2 , respec- tively. These values are consistent with those obtained by previous studies (Michikami et al., 2008 (global: $3.1 \pm 0.11$, head: $2.8 \pm 0.1$, body: $3.2 \pm 0.1$, east: $2.9 \pm 0.1$, west: $3.2 \pm 0.1$ ), Mazrouei et al., 2014 (head: $3.1 \pm 0.4$, body: $3.6 \pm 0.2$ ), Tancredi et al., 2015 (head: $2.96 \pm 0.36,-3.6 \pm 0.2)$ ), further validating our method based on radiance variation. The standard deviation of $\alpha$ calculated for the entire surface of Itokawa is 0.83 , which is much larger than that of Ryugu. This large variation reflects the boulder distribution contrast in smooth regions with few boulders (Muses Sea, Saga mihara) and other rougher surfaces on Itokawa. This difference could be due to granular motion, which is thought to have transported small particles to the lowpotential regions (Miyamoto et al., 2007). In contrast, our results suggest that such an effect is not prominent on Ryugu possibly because of different particle sizes and densities, cohesive forces, the symmetric shape, the large size or the high porosity of Ryugu.

\subsection{Typical boulder size on ryugu}

The ty pical boulder size (i.e., the size at which the cumulative coverage reaches 50\%) was calculated from the SFDs of different longitudinal/latitudinal bins. We found that the typical boulder size is $1.9 \mathrm{~m}$ at the equatorial region $\left(10^{\circ} \mathrm{S}-10^{\circ} \mathrm{N}\right)$ and $2.6 \mathrm{~m}$ at mid-latitudes $\left(40^{\circ} \mathrm{S}\right.$ $50^{\circ} \mathrm{S}, 40^{\circ} \mathrm{N}-50^{\circ} \mathrm{N}$ ) (Fig. 14a). We also found an east-west contrast in typical boulder size (Fig. 14b).

\subsection{Comparison with $v$-band albedo and topographic slope}

Because our analysis yields the global maps of small-scale roughness and power-law index of boulder size distribution, they can be compared with different observables that characterize the asteroidal surfaces (Fig. 15). For example, the v-band albedo shows little correlation with $\sigma_{s p}(\mathrm{R}=0.34)$, while the albedo shows a higher correlation with the power-law index $(\mathrm{R}=0.58)$ (Fig. 16). The reason for the higher correlation between the power-law index and the v-band albedo is unknown, but one hypothesis would be that size-sorting processes on
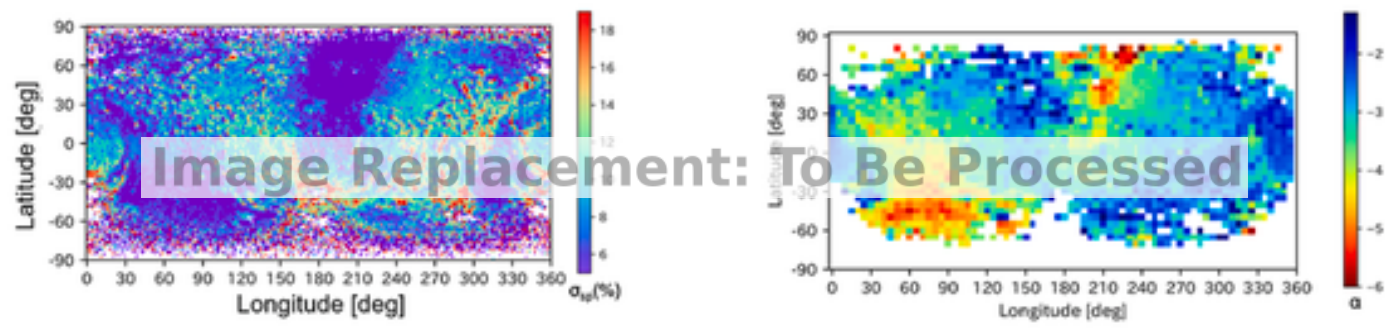

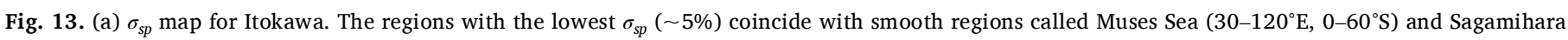

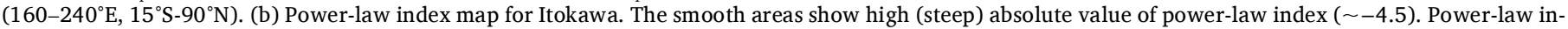

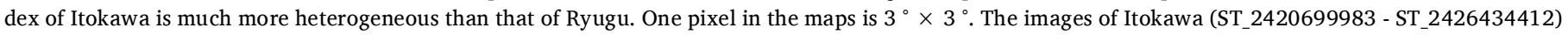
were used to produce these global maps. 
(a)

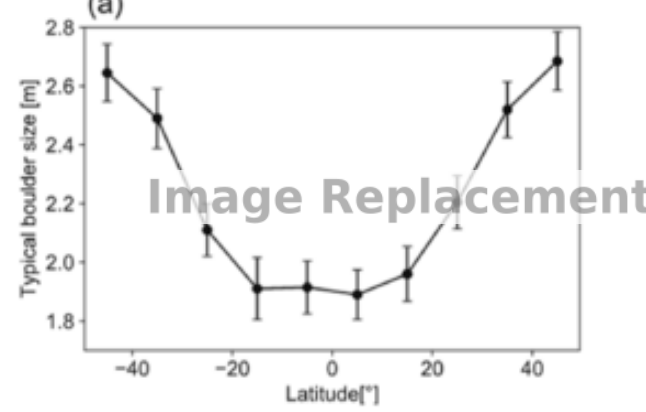

(b)

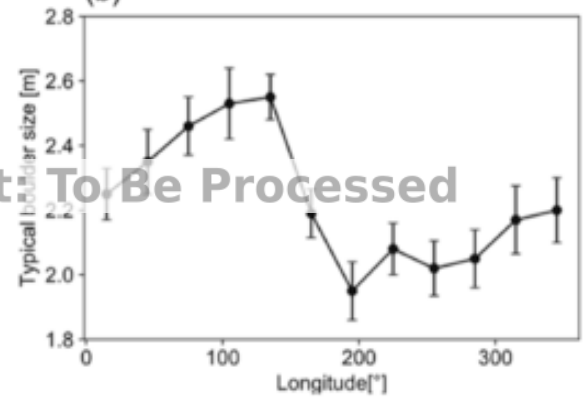

Fig. 14. Typical boulder size (the size reaching the cumulative areal coverage of 50\%) in different (a) latitudes and (b) longitudes.

(a) Geological slope [deg]

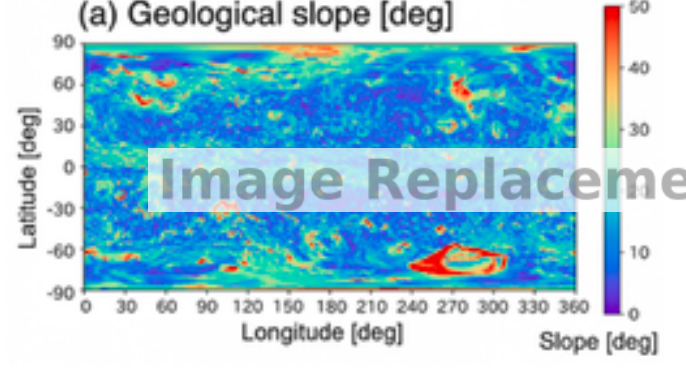

(b) v-band albedo

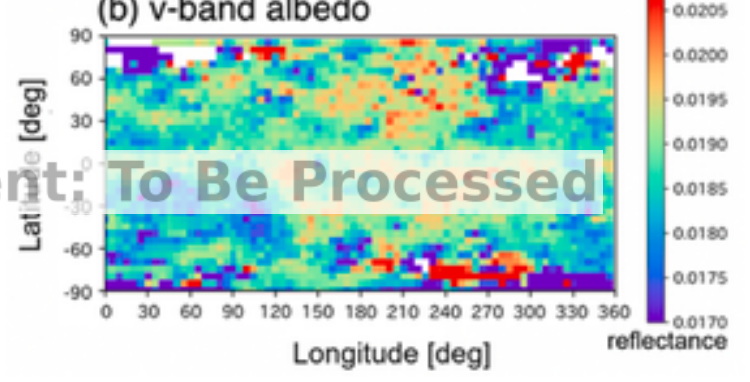

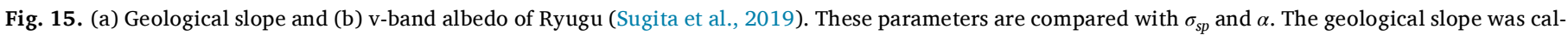

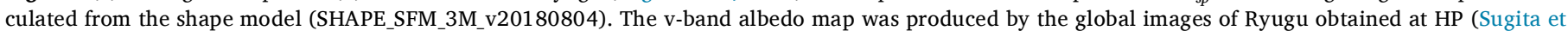
al., 2019).

Ryugu, which would change the values of $\alpha$, made the variation of $\mathrm{v}$ band albedo. Second, $\sigma_{s p}$ and the current geological slope exhibit a high anti-correlation $(\mathrm{R}=-0.73)$ on the eastern hemisphere (latitudes $0-45^{\circ}$ ) (Fig. 13), while the western bulge shows a weaker correlation $(\mathrm{R}=-0.49)$. The substantial negative correlation in the eastern hemisphere indicates that fewer boulders occur on slopes and more boulders sit on the plain. This distribution is consistent with the interpretation that the boulders migrated to the current gravity low, suggesting that the relocation of boulders took place after the spin state slowed down to the current level (Watanabe et al., 2019). The reason for the low correlation in the western bulge is unclear, but it might be because the western bulge is younger than the eastern hemisphere (Cho et al. in revision) and boulders are currently gravitationally unstable. This trend suggests that the distribution of boulders on the equatorial region slid down along with the current geopotential, not with that of the paleo high-spin-rate era, and it created the mass flow features reported by Sugita et al. (2019).

\section{Conclusions}

We developed a novel method to estimate the abundance of boulders of 1.5-6 pixels by measuring the standard deviation of radiance $\left(\sigma_{s p}\right)$ that individual pixels exhibit as an asteroid spins. Then we calibrated the coverage of regions having $\sigma_{s p}>0.1$ with the coverage of boulders. This calibration yielded a boulder coverage consistent with those obtained in a previous study of Ryugu, which wa s conducted by visual counting (Michikami et al., 2019). From a comparison with this published boulder coverage, the root mean square error of our prediction was determined to be $1.85 \%$, when the median boulder coverage was $30 \%$. This level of uncertainty is comparable to the intrinsic uncertainty of visual boulder counting.

Using this method, we obtained the global distribution of boulders of $0.75-3 \mathrm{~m}$ (1.5-6 pixels), which is otherwise not possible to extract visually due to the resolution limit. We found that the boulder number density is smaller (1) on the western bulge than on the eastern hemisphere and (2) on the equatorial ridge than on the higher latitudes, both of which extend the global trend reported for boulders $>5 \mathrm{~m}$ (Sugita et al., 2019; Michikami et al., 2019) to a sub-meter scale. The latitudedependent SFDs using the boulders of $1.25-20 \mathrm{~m}$ in size show that boulders smaller than $1 \mathrm{~m}$ are more abundant at the equator than at midlatitudes, while those larger than $1 \mathrm{~m}$ are more abundant at midlatitudes than at the equator (Fig. 11). This different crossover in boulder SFD depending on latitudes could be because of the size-dependent mobility of boulders.

The SFD of boulders of $1.25-10 \mathrm{~m}$ was derived globally by changing the pixel resolution through binning the original images. The global map of the power-law index $\alpha$ shows a very small variation in $\alpha$ over the entire Ryugu (Fig. 12). The small va riation in $\alpha(-2.53 \pm 0.03)$ suggests that the lateral boulder size-sorting process is either weak or very homogeneous on Ryugu, producing no particularly smooth regions and other rough regions as observed on Itokawa. The power-law index for the boulders of $1.25-10 \mathrm{~m}$ is consistent with that reported for the boulders larger than $5 \mathrm{~m}$ on Ryugu (Michikami et al., 2019).

Using the SFDs of different longitudinal/latitudinal bins, we found that the typical boulder size (i.e., the cumulative coverage reaches $50 \%)$ is $1.9 \mathrm{~m}$ at the equatorial region $\left(10^{\circ} \mathrm{S}-10^{\circ} \mathrm{N}\right)$ and $2.6 \mathrm{~m}$ at midlatitudes $\left(40^{\circ} \mathrm{S}-50^{\circ} \mathrm{S}, 40^{\circ} \mathrm{N}-50^{\circ} \mathrm{N}\right)$. We also found an east-west contrast in typical boulder sizes.

The application of our technique to Itokaw a images demonstrated that smooth areas, such as Muses Sea and Saga mihara, can be detected by our approach. The power-law index of the SFD showed a remarkable difference betw een the smooth areas and other rougher areas.

The roughness index $\sigma_{s p}$ and power-law index $\alpha$ were compared with the v-band albedo and geologic slopes on Ryugu. We found that the vband albedo shows little correlation with $\sigma_{s \mathrm{p}}(\mathrm{R} \sim 0.34)$, but shows a higher correlation with the power-law index $(\mathrm{R} \sim 0.58)$. Although a different power-law index suggests that this is the result of size sorting (e.g., very steep $\alpha$ in the smooth region on Itokawa), the reason for the higher correlation between the power-law index and v-band albedo is unknown: it is possible that size-sorting processes affect the v-band albedo. The surface roughness $\sigma_{s p}$ and current geological slope show a high anti-correlation $(\mathrm{R} \sim-0.73)$ on the eastern hemisphere. This anti- 


\section{(a) $\alpha$ vs v-band albedo}

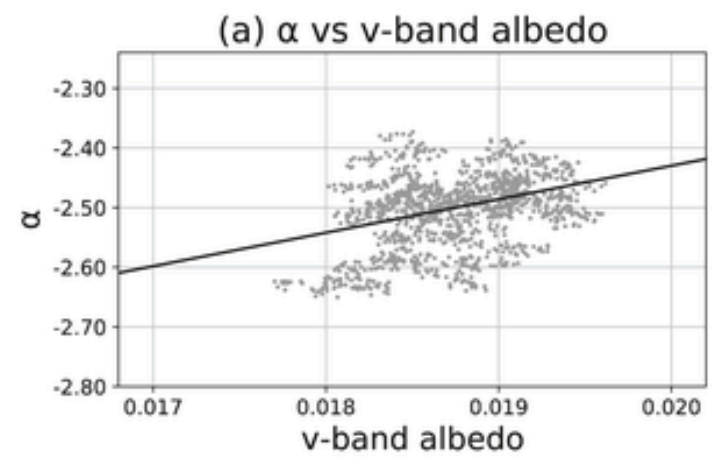

\section{Image Replacement: To Be Processed}

\section{(b) $\sigma_{s p}$ vs geological slope}
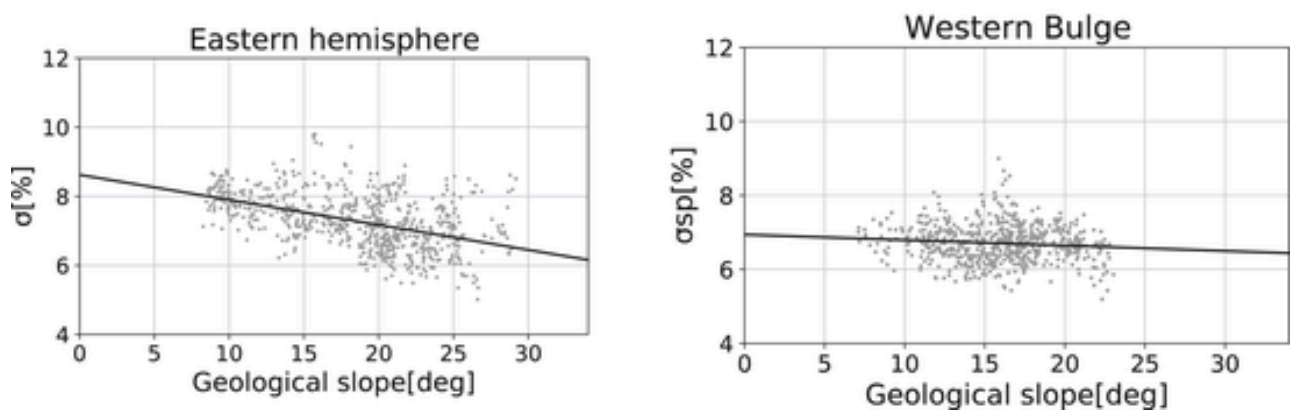

Fig. 16. Correlation between (a) power-law index and v-band albedo $\left(45^{\circ} \mathrm{S}\right.$ to $\left.45^{\circ} \mathrm{N}\right)$, (b) $\sigma_{s p}$ and geological slopes in the two hemispheres. The global maps of power-law index $\alpha$ (Fig. 8) and $\sigma_{s p}$ (Fig. 12) were correlated with the geological slope derived from the shape model of Ryugu (SHAPE_SFM_3M_v20180804).

correlation is consistent with the interpretation that the relocation of boulders occurred after the spin rate of Ryugu slowed down to the current speed.

The results of this study demonstrated that the newly developed method of boulder analysis without extensive visual counting can be used for the smooth area detection and boulder distribution characterization. This approach would be useful for other planetary explorations in the future, including other asteroids as well as Mars' moon Phobos and other asteroids.

\section{Author statement}

Y. Cho: Conceptualization, Methodology, Resources, Supervision, Writing - Review \& Editing; E. Tatsumi: Conceptualization, Methodology, Resources, Supervision, Writing - Review \& Editing; T. Ebihara: Conceptualization, Methodology, Validation, Formal analysis, Visualization; K. Yumoto: Conceptualization, Methodology, Validation, Formal analysis, Visualization; T. Michikami: Conceptualization, Validation; H. Miyamoto: Conceptualization, Resources; T. Morota: Conceptualization, Methodology, Resources; C. Honda: Conceptualization, Validation, Resources; P. Michel: Conceptualization, Methodology, Writing - Review \& Editing; K. A. Otto: Conceptualization, Methodology, Writing - Review \& Editing; O. S. Barnouin: Conceptualization, Methodology, Writing - Review \& Editing; K. Yoshioka: Conceptualization, Resources; H. Sawada: Conceptualization, Resources; Y. Yokota: Conceptualization, Re- sources; N. Sakatani: Conceptualization, Resources; M. Hayakawa: Conceptualization, Resources; R. Honda: Conceptualization, Resources; S. Kameda: Conceptualization, Resources; M. Matsuoka: Conceptualization, Resources; M. Yamada: Conceptualization, Resources; T. Kouyama: Conceptualization, Resources; H. Suzuki: Conceptualization, Resources; K. Ogawa: Conceptualization, Resources; Seiji Sugita: Conceptualization, Methodology, Resources, Supervision, Writing - Review \& Editing.

\section{Uncited References}

Michel and Richardson, 2014,

\section{Declaration of competing interest}

The authors declare that they have no known competing financial interests or personal relationships that could have appeared to influence the work reported in this paper.

\section{Acknowledgements}

This study was supported by KAKENHI from the Japanese Society for Promotion of Science (JSPS) (Grant Numbers 19K14778, 20H04607) and the JSPS Core-to-Core program "International Network of Planetary Sciences." P.M. acknowledges support from the French space agency, CNES and from the European Union's Horizon 
2020 research and innovation program under grant agreement No 870377 (project NEO-MAPP), and from Academies of Excellence: Complex systems and Space, environment, risk, and resilience, part of the IDEX JEDI of the Université Côte d'Azur.

\section{References}

Cho, Y. T. Morota, M. Kanamaru, N. Takaki, K. Yumoto, C. M. Ernst, M. Hirabaya shi, O. S. Barnouin, E. Tatsumi, K. A. Otto, N. Schmitz, R. J., Wagner, R. Jaumann, H. Miyamoto, H. Kikuchi, R. Hemmi, R. Honda, S., Ka meda, Y. Yokota, T. Kouyama, H. Suzuki, M. Ya ma da, N. Saka tani, C., Honda, M. Ha ya kawa, K. Yoshioka, M. Ma tsuoka, T. Michikami, N. Hi ra ta, H. Sawada, K. Ogawa, and S. Sugita, Geologic history and crater morphology of as teroid (162173) Ryugu, J. Geophs. Res.. in revision.

Daly, T., R., Schultz, H., P., 2016. Delivering a projectile component to the vestan regolith. Icar us 264, 9-19.

Dombard, A.J., Barnouin, O.S., Prockter, L.M., Thom as, P.C., 2010. Boulders and ponds on the asteroid 433 eros. Icar us 210, 713-721.

Durda, D., Greenberg, R., D., Jedicke, R., 1998. Collisional models and scaling laws: a new interpretation of the shape of the main-belt asteroid size distribution, icar us 135,. Issue 2, 431-440.

Fuji wara, A., Ka waguchi, J., Yeomans, D.K., Abe, M., Mukai, T., Okada, T., Saito, J., Yano, H., Yoshikawa, M., Scheeres, D.J., Barnouin-Jha, O., Cheng, A.F., Demura, H., Gaskell, R.W., Hirata, N., Ikeda, H., Komi nato, T., Mi ya mo to, H., Nakamura, A.M., Nakamura, R., Sa sa ki, S., Uesugi, K., 2006. The rubble-pile asteroid Itokawa as observed by Hayabusa. Science 312 , 1330-1334.

Hartma nn, W.K., 1969. Terrestrial, lunar, and interplanetary rock frag mentation. Icar us $10,201-213$.

Jawin, E.R., Walsh, K.J., Barnouin, O.S., McCoy, T.J., Ballouz, R.L., DellaGiustina, D.N., Connolly, Jr., H.C., Marshall, J., Beddingfield, C., Nolan, M. C., Mola ro, J.L., Bennett, C. A., Scheeres, D.J., Daly, M. G., Al Asad, M., Daly, R.T., Bierhaus, E.B., Susorney, H.C.M., Kaplan, H.H., Enos, H. L., Lauretta, D.S., 2020. Global patterns of recent mass movement on as teroid (101955) Bennu. JGR Planets 125.

Kanama ru, M., Sa sa ki, S., 2019. Estimation of interior density distribution for small bodies: the case of as teroid Itokawa. Trans. JSASS aerospace tech. Jpn. Times 17 (No. 3), 270-275.

Kikuchi, S., Watanabe, S., Yabuta, H., Sugita, S., Morota, T., Hirata, N., Hira ta, N., Michikami, T., Honda, C., Yokota, Y., Honda, R., Sakatani, N., Okada, T., Shimaki, Y., Matsumoto, K., Noguchi, R., Takei, Y., Terui, F., Ogawa, N., Yoshikawa, K., Ono, G., Mima su, Y., Sa wada, H., Ikeda, H., Hi rose, C., Taka hashi, T., Fujii, A., Yamaguchi, T., Ishihara, Y., Nakamura, T., Kitazato, K., Wada, K., Tachibana, S., Tatsumi, E., Matsuoka, M., Senshu, H., Ka meda, S., Kouyam a, T., Yama da, M., Shirai, K., Cho, Y., Og awa, K., Ya ma mo to, Y., Mi ura, A., Iwata, T., Nami ki, N., Ha ya kawa, M., Abe, M., Tanaka, S., Yoshikawa, M., Nakazawa, S., Tsuda, Y., 2020. Hayabusa 2 landing site selection: surface topography of Ryugu and touchdown safety. Space Sci. Rev. $216,116$.

La uretta, D.S., DellaGiustina, D.N., Bennett, C.A., Golish, D.R., Becker, K. J., Balram-Knutson, S.S., Barnouin, O.S., Becker, T.L., Bottke, W.F., Boynton, W. V., Campins, H., Clark, B.E., Connolly, H.C., Drouet d'Aubigny, C.Y., Dworkin, J.P., Emery, J.P., Enos, H. L., Ha milton, V.E., Herg enrother, C.W., Howell, E.S., Izawa, M. R. M., Ka plan, H.H., Nolan, M.C., Rizk, B., Roper, H. L., Scheeres, D.J., Sm ith, P.H., Walsh, K. J., Wolner, C. W.V., Os ir is-REx Team, 2019. The unexpected surface of as teroid (101955) Bennu. Nature 568, 55-60.

Lowry, C., S., Weissman, R., P., Duddy, R., S., Rozitis, B., Fitzsimm ons, A., Green, F., S., Hicks, D., M., Snodgras s, C., Wolters, S.D., Chesley, R., S., Pittichova, J., van Oers, P., 2014. The internal structure of as teroid (25143) Itokawa as revealed by detection of YORP spin-up. Astron. Astrophys. 562, A48.

Mazrouei, S., Daly, M.G., Barnouin, O.S., Ernst, C.M., DeSouza, I., 2014. Block distributions on Itokawa. Icar us 229, 181-189.

Michikami, T., Nakamura, A.M., Hira ta, N., Gaskell, R.W., Nakamura, R., Honda, T., Honda, C., Hira oka, K., Saito, J., Demura, H., Ishiguro, M., Mi ya mo to, H., 2008. Size-frequency statistics of boulders on global surface of as teroid 25143 Itokawa. Earth Planets Space 60, 13-20.

Michel, P., Richardson, C., D., 2014. Collision and gravitational reaccumulation: possible formation mechanism of the asteroid Itokawa. Asteronomy and astrophysics 554, L1.

Michikami, T., Honda, C., Miya moto, H., Hira bayashi, M., Hagerm ann, A., Irie, T., Nomura, K., Ernst, C.M., Kawamura, M., Sugimoto, K., Tatsumi, E., Morota, T., Hirata, N., Noguchi, T., Cho, Y., Kameda, S., Kouyama, T., Yokota, Y., Noguchi, R., Ha yaka wa, M., Hira ta, N., Honda, R., Ma tsuoka, M., Sa ka tani, N., Suzuki, H., Ya ma da, M., Yoshioka, K., Sa wada, H., Hemm i, R., Kikuchi, H., Og awa, K., Watanabe, S., Tanaka, S., Yoshikawa, M., Tsuda, Y., Sugita, S., 2019. Boulder size and shape distributions on as teroid Ryugu. Icar us 331, 179-191.

Miya mo to, H., Ya no, H., Scheeres, D.J., Abe, S., Barnouin-Jha, O., Cheng, A.F., Demura, H., Gaskell, R.W., Hirata, N., Ishiguro, M., Michikami, T., Nakamura, A.M., Nakamura, R., Saito, J., Sa saki, S., 2007. Science 316, 1011-1014.

Mottola, S., Arnold, G., Grothues, H. G., Jaumann, R., Michaelis, H., Neukum, G., Bibring, J.P., Schröder, S.E., Hamm, M., Otto, K.A., Pelivan, I., Proffe, G.,
Scholten, F., Tirsch, D., Kreslavsky, M., Remetean, E., Souvannavong, F., Dolives, B., 2015. The structure of the regolith on 67P/ChuryumovGera simenko from ROLIS descent imag ing. Science 349, aab0232.

Murdoch, N., Sanchez, P., Schwartz, S.R., Miyamoto, H., 2015. Asteroid Surface Geophysics, in Asteroids IV. University of Arizona Press, Tucson, pp. 767-792.

Nakamura, A.M., Michikami, T., Hira ta, N., Fujiwara, A., Nakamura, R., Ishiguro, M., Miya mo to, H., Demura, H., Hira oka, K., Honda, T., Honda, C., Saito, J., Ha shimoto, T., Kubota, T., 2008. Impact process of boulders on the surface of as teroid 25143 Itokawa -Frag ments from collisional disruption. Earth Planet. Space 60, 7-12.

Pajola, M., Vincent, J.-B., Güttler, C., Lee, J.-C., Bertini, I., Ma ss ironi, M., Simi oni, E., Marzari, F., Giacom ini, L., Lucchetti, A., Barbieri, C., Cremonese, G., Naletto, G., Pomm erol, A., El-Ma ar ry, M.R., Bess e, S., Küppers, M., La Forg ia, F., Lazzarin, M., Thom as, N., Auger, A., Sierks, H., Lamy, P., Rodrigo, R., Koschny, D., Rickma n, H., Keller, H. U., Agarwal, J., A'Hearn, M. F., Barucci, M.A., Bertaux, J., Deppo, V.D., Davidsson, B., De Cecco, M., Debei, S., Ferri, F., Fornasier, S., Fulle, M., Grouss in, O., Gutierrez, P.J., Hviid, S. F., Ip, W., Jorda, L., Knollenberg, J., Kram m, J.-R., Kürt, E., La ra, L.M., Lin, Z., Moreno, J.J.L., Magrin, S., Marchi, S., Michalik, H., Moissl, R., Mottola, S., Oklay, N., Preusker, F., Scholten, F., Tubiana, C., 2015. Size-frequency distribution of boulders C7 m on comet 67P/Churyumov-Gera simenko. Astron. Astro Phys 583, A37.

Phillips, J.C., Hogg, A.J., Kerswell, R. R., Thom as, N.H., 2006. Enhanced mobility of granular mixtures of fine and coarse particles. Earth Planet Sci. Lett. 246, $466-480$.

Saito, J., Miyamoto, H., Nakamura, R., Ishiguro, M., Michikami, T., Nakamura, A.M., Demura, H., Sa sa ki, S., Hira ta, N., Honda, C., Ya ma moto, A., Yokota, Y., Fuse, T., Yoshida, F., Tholen, D.J., Gask ell, R.W., Ha shim oto, T., Kubota, T., Higuchi, Y., Nakamura, T., Sm ith, P., Hira oka, K., Honda, T., Kobayashi, S., Furuya, M., Matsumoto, N., Nemoto, E., Yukishita, A., Kitazato, K., Derm aw an, B., Soga me, A., Tera zono, J., Shinohara, C., Akiyam a, H., 2007. Detailed images of as teroid 25143 Itokaw a from Hayabusa. Science 312 (5778), 1341-1344.

Sugita, S., Honda, R., Morota, T., Kameda, S., Sa wada, H., Tatsumi, E., Yama da, M., Honda, C., Yokota, Y., Kouyama, T., Sa katani, N., Og awa, K., Suzuki, H., Okada, T., Namiki, N., Tanaka, S., Iijima, Y., Yoshioka, K., Ha ya kawa, M., Cho, Y., Ma tsuoka, M., Hirata, N., Hira ta, N., Miya moto, H., Domingue, D., Hira baya shi, M., Nakamura, T., Hi roi, T., Michikam i, T., Michel, P., Ballouz, R.-L., Barnouin, O.S., Ernst, C.M., Schroder, S.E., Kikuchi, H., Hemmi, R., Komatsu, G., Fukuhara, T., Taguchi, M., Arai, T., Senshu, H., Demura, H., Og awa, Y., Shimaki, Y., Sekiguchi, T., Muller, T.G., Ha germ ann, A., Mizuno, T., Noda, H., Ma tsumoto, K., Ya ma ra, R., Ishihara, Y., Ikeda, H., Araki, H., Ya ma moto, K., Abe, S., Yoshida, F., Higuchi, A., Sa saki, S., Oshiga mi, S., Tsuruta, S., Asari, K., Tazawa, S., Shizugami, M., Kimura, J., Otsubo, T., Yabuta, H., Ha sega wa, S., Ishiguro, M., Tachibana, S., Palm er, E., Gaskell, R., Corre, L. L., Jaumann, R., Otto, K., Schmitzu, N., Abell, A., P., Barucci, A., M., Zolensky, E., M., Vilas, F., Thuillet, F., Sugimoto, C., Takaki, N., Suzuki, Y., Kami yoshihara, H., Okada, M., Naga ta, K., Fujimoto, M., Yoshikawa, M., Ya ma mo to, Y., Shirai, K., Noguchi, R., Og awa, N., Terui, F., Kikuchi, S., Ya ma guchi, T., Oki, Y., Taka o, Y., Takeuchi, H., Ono, G., Mimasu, Y., Yoshikawa, K., Takahashi, T., Takei, Y., Fujii, A., Hirose, C., Nakazawa, S., Hosoda, S., Mori, O., Shimada, T., Soldini, S., Iwata, T., Abe, M., Ya no, H., Tsukizaki, R., Ozaki, M., Nishikawa, K., Saiki, T., Watanabe, S., Tsuda, Y., 2019. The geomorphology, color, and thermal properties of Ryugu: implications for parent-body processes. Science 364 (6437) eaaw 0422.

Tanaka, H., Inaba, S., Nakazawa, K., Size, S.-S., 1996. Steady-State Size Distribution for the self-similar collision cascade. Icar us 123, 450-455. Tancredi, G., Roland, S., Bruzzone, S., 2015. Distribution of boulders and the gravity potential on as teroid Itokawa. Icar us 247, 279-290.

Tatsumi, E., Domingue, D., Schröder, S., Yokota, Y., Kuroda, D., Ishiguro, M., Ha sega wa, S., Hiroi, T., Honda, R., Hemm i, R., Le Corre, L., Sakatani, N., Morota, T., Ya ma da, M., Kameda, S., Koyama, T., Suzuki, H., Cho, Y. Yoshioka, K., Matsuoka, M., Honda, C., Hayakawa, M., Hira ta, N., Hira ta, N., Ya ma moto, Y., Vilas, F., Taka to, N., Yoshikawa, M., Abe, M., Sugita, S., July 2020. Global photometric properties of (162173) Ryugu, as tronomy and as trophysics 639

Thom as, P.C., Veverka, J., Robinson, M.S., Murchie, S., 2001. Shoema ker crater as the source of most ejecta blocks on the as teroid 433 Eros. Nature 413 , 394-396.

Turcotte, D.L., Fractals and Chaos in Geology and Geophysics (Cup), 1997k.

Walsh, K., Einasto, J., Motte, F., Bontemps, S., Louvet, F., Bastian, N., Lardo, C., Nesv orny, D., Dawson, I., R., Jobson, A., J., Barbuy, B., Cbiappini, C., Gerbard, O., Riga ut, F., Neibel, B., Guyon, O., Stern, S.A., Grundy, M., McKinnon, B., W., Weaver, H. A., Young, A., L., Mandelbaum, R., Websler, R. H., Tinke, J.L., Stanimirovic', S., Zweibel, E.G., Hugbes, M., A., Duchêne, G., Ma ttbew, C., Hickox, C., R., Alexander, M., D., Galliano, F., Gala metz, M., Jones, P., A., 2018. Rubble pile as tero ids. Annu. Rev. Astron. Astrophys. 56, 593-624.

Walsh, K.J., Jawin, E.R., Ballouz, R.-L., Barnouin, O.S., Bierhaus, E.B., Connolly, Jr., H.C., Molaro, J.L., McCoy, T.J., Delbo', M., Hartzell, C. M., Pajola, M., Schwartz, S.R., Trang11, D., Asphaug, E., Becker, K. J., Beddingfield1, C.B., Bennett, C. A., Bottke, W.F., Burke, K. N., Clark, B.C., Daly, M. G., DellaGiustina, D.N., Dworkin, J.P., Elder, C. M., Golish, D.R., Hildebrand1, A. R., Malhotra, R., Marshall1, J., Michel, P., Nolan, M.C., Perry, M.E., Rizk, B., Ryan, A., Sandford1, S. A., Scheeres, D.J., Susorney, H.C.M., Thuillet, F., Lauretta, D.S., The Os iris-REx Team, 2019. Craters, boulders, and regolith of 
(101955) indicative of an old and dynamic surface. Nat. Geosci. 12, 242-246.

Watanabe, S., Hi ra baya shi, M., Hira ta, N., Hira ta, N., Noguchi, R., Shimaki, Y. Ikeda, H., Tatsumi, E., Yoshikawa, M., Kikuchi, S., Ya buta, H., Naka mura, T., Tachibana, S., Ishihara, Y., Morota, T., Kitazato, K., Sakatani, N.,

Ma tsum oto, K., Wada, K., Senshu, H., Honda, C., Michikami, T., Takeuchi, H., Kouyama, T., Honda, R., Kameda, S., Fuse, T., Miya moto, H., Koma tsu, G., Sugita, S., Okada, T., Nami ki, N., Arakawa, M., Ishiguro, M., Abe, M., Gask ell, R., Palmer, E., Barnouin, S., O., Michel, P., French, S., A., McMahon, W., J., Scheeres, D.J., Abell, A., P., Yama moto, Y., Tanaka, S., Shirai, K., Ma tsuoka, M., Yama da, M., Yokota, Y., Suzuki, H., Yoshioka, K., Cho, Y.,
Tanaka, S., Nishikawa, N., Sugitayama, T., Kikuchi, H., Hemmi, R., Ya ma guchi, T., Og awa, N., Ono, G., Mimasu, Y., Yoshikawa, K., Takahashi, T., Takei, Y., Fujii, A., Hi rose, C., Iwata, T., Hayakawa, M., Hoso da, S., Mori, O., Sa wada, H., Shimada, T., Soldini, S., Ya no, H., Tsukizaki, R.,

Ozaki, M., Iijima, Y., Og awa, K., Fujimoto, M., Ho, T.-M., Moussi, A.,

Jaumann, R., Bibring, J.-P., Krause, C., Terui, F., Saiki, T., Nakazawa, S., Tsuda, Y., 2019. Hayabusa 2 ar rives at the carbonaceous as teroid 162173

Ryugu-A spinning top-shaped rubble pile. Science 364 (6437), 268-272. 